\title{
Monitoring of Osteonecrosis in Systemic Lupus Erythematosus: A Systematic Review and Metaanalysis
}

\author{
Sara Hussein, Manon Suitner, Sarah Béland-Bonenfant, Alexandra Baril-Dionne, \\ Ben Vandermeer, Nancy Santesso, Stephanie Keeling, Janet E. Pope, Aurore Fifi-Mah, \\ and Josiane Bourré-Tessier
}

ABSTRACT. Objective. Nontraumatic osteonecrosis (ON) is a well-recognized complication causing disability and affecting quality of life in patients with systemic lupus erythematosus (SLE). The aim of this study was to identify the risk factors for ON, and to identify the minimal investigation(s) needed to optimally monitor the risk of ON in patients with SLE.

Methods. A systematic review was conducted using MEDLINE and EMBASE. These databases were searched up to January 2016 using the Medical Subject Heading (MeSH) terms "Osteonecrosis," "Systemic lupus erythematosus," and synonymous text words. Randomized controlled trials, case control, cohort, and cross-sectional studies were included. Risk factors for ON in patients with SLE were compiled. The quality of each study was assessed using the Newcastle-Ottawa scale for nonrandomized studies. The quality of evidence of each risk factor was assessed using the Grading of Recommendations, Assessment, Development, and Evaluation method.

Results. Of the 545 references yielded, 50 met inclusion criteria. Corticosteroid (CS) use may be strongly associated with $\mathrm{ON}$ in patients with SLE. Other clinical variables were moderately associated, including hypertension, serositis, renal disease, vasculitis, arthritis, and central nervous system disease. However, the evidence was low to very low in quality.

Conclusion. Based on the best evidence available, CS use may be strongly associated with ON in patients with SLE. Results of this review were considered in the development of recommendations for the diagnosis and monitoring of patients with SLE in Canada and will guide clinicians in their assessment of these patients. (First Release July 1 2018; J Rheumatol 2018;45:1462-76; doi:10.3899/ jrheum.170837)

Key Indexing Terms:

SYSTEMIC LUPUS ERYTHEMATOSUS OSTEONECROSIS METAANALYSIS REVIEW

From the Department of Medicine, University of Montréal, Montréal, Quebec; Alberta Research Center, and Department of Medicine, University of Alberta, Edmonton, Alberta; Department of Clinical Epidemiology and Biostatistics, McMaster University, Hamilton; Department of Medicine, Western University of Canada, London, Ontario; Department of Medicine, University of Calgary, Calgary, Alberta, Canada.

S. Hussein, MD, Rheumatology Resident, Department of Medicine, University of Montreal; M. Suitner, MD, Rheumatology Resident, Department of Medicine, University of Montreal; S. Béland-Bonenfant, MD, Internal Medicine Resident, Department of Medicine, University of Montreal; A. Baril-Dionne, MD, Rheumatology Resident, University of Montréal; B. Vandermeer, MSc, biostatistician, Alberta Research Center, University of Alberta; N. Santesso, RD, MLIS, PhD, Assistant Professor, Department of Clinical Epidemiology and Biostatistics, McMaster University; S. Keeling, MD, MSc, FRCPC, Associate Professor, Division of Rheumatology, Department of Medicine, University of Alberta; J.E. Pope, $M D, M P H, F R C P C$, Professor of Medicine, University of Western Ontario, Division Head, Rheumatology; A. Fifi-Mah, MD, FRCPC, Clinical Assistant Professor, Arthritis Diseases Clinic, University of Calgary; J. Bourré-Tessier, MD, MSc, FRCPC, Clinical Assistant Professor, Division of Rheumatology, Department of Medicine, University of Montreal.

Address correspondence to Dr. J. Bourré-Tessier, Service de rhumatologie, CHUM, 264 Blvd. René-Lévesque Est, Montreal, Québec H2X 1P1,

Canada.E-mail: josiane.bourre.tessier@umontreal.ca

Full Release Article. For details see Reprints and Permissions at jrheum.org Accepted for publication February 16, 2018.
Osteonecrosis $(\mathrm{ON})$, also known as avascular necrosis of the bone, is a well-recognized complication in systemic lupus erythematosus (SLE). The clinical presentation of ON is variable; it may be clinically silent or present with gradual-onset pain that can progress to severe pain, bone collapse, and joint damage, causing restriction of the range of motion and eventually requiring total joint arthroplasty. The prevalence of ON in patients with SLE ranges between $10 \%$ and $15 \%$, but can reach as high as $44 \%$ when asymptomatic lesions are included ${ }^{1,2}$. Multifocal $\mathrm{ON}$ is frequent in patients with SLE; bilateral hip ON has been reported to occur in up to $90 \%$ of patients with SLE who have $\mathrm{ON}^{2}$.

Previous studies have demonstrated that symptomatic ON frequently causes disability and considerably affects quality of life ${ }^{3}$, as measured by the Health Assessment Questionnaire and/or the 20-item Short Form Health Survey (SF-20) ${ }^{4,5}$. As shown by the presence of the item "avascular necrosis" in the Systemic Lupus International Collaborating Clinics/ American College of Rheumatology (ACR) Damage Index for SLE, ON is a well-recognized feature of the accumulated damage in SLE ${ }^{6}$.

Personal non-commercial use only. The Journal of Rheumatology Copyright $\odot$ 2018. All rights reserved 
The pathophysiology of $\mathrm{ON}$ is not completely understood. It is likely the result of the combined effects of genetic predisposition, metabolic factors, and other factors affecting blood supply ${ }^{7}$. Ultimately, ON is characterized by bone death, which may be due to traumatic or atraumatic factors decreasing blood supply or causing osteotoxicity. Many theories regarding the mechanisms leading to blood interruption have been proposed and include increased bone marrow pressure and intravascular occlusion of subchondral vessels by coagulation, fat emboli, thrombi, or abnormally shaped red blood cells. Moreover, direct osteotoxicity by alcohol and drugs can lead to bone cell death ${ }^{8}$. Although the use of corticosteroids (CS) has been recognized as a major risk factor for the development of ON, ON occurs more frequently in patients with SLE than in any other illness requiring administration of systemic $\mathrm{CS}^{9}$. This suggests that the use of CS may not be the only risk factor associated with the development of ON in patients with SLE. As part of the development of Grading of Recommendations, Assessment, Development, and Evaluation (GRADE)-based Canadian recommendations in SLE, we conducted this systematic literature review to determine the different risk factors for $\mathrm{ON}$ in patients with SLE. The specific question addressed was, "what are the minimum investigation(s) necessary to optimally monitor the risk of ON in SLE patients?" To answer this question, the identification of all the risk factors associated with ON in SLE was necessary, and that was the goal of our present study.

\section{MATERIALS AND METHODS}

Search strategy. A comprehensive and systematic search was performed using MEDLINE and EMBASE. Each database was searched from its inception to January 2016 in both French and English. A broad combination of Medical Subject Heading (MeSH) terms included "Systemic lupus erythematosus," "Osteonecrosis," "Aseptic necrosis," "Avascular necrosis," "Femur head necrosis," and synonymous text words. Additional articles were retrieved by hand-searching relevant references and guidelines, especially European League Against Rheumatism recommendations ${ }^{10,11}$ and ACR Appropriateness Criteria ${ }^{12}$. Ethics board approval for a systematic review and metaanalysis was not required, in accordance with the policy of our institution (Centre Hospitalier de l'Université de Montréal). The end date for the search represents when this review was completed for the results to be used for the GRADE-based recommendations for assessment and monitoring of SLE in Canada; therefore, the search was not further updated, to ensure consistency of data.

Study selection. Two reviewers (SH and MS) screened all articles based on titles and abstracts and selected potentially eligible studies. Full-text articles of all relevant studies were retrieved and assessed for inclusion, based on specific eligibility criteria: (1) randomized controlled trials (RCT), case control, cohort, or cross-sectional studies; (2) patients diagnosed with SLE (according to authors of the articles); (3) symptomatic and/or asymptomatic ON (any joint could be affected); (4) ON confirmed by 1 or more of the following methods: conventional radiography, bone scan, magnetic resonance imaging (MRI), tomograms, or histology; and (5) reporting of at least 1 risk factor for ON. Exclusion criteria included any of the following: (1) case reports, letters, and review articles; (2) non-human studies; and (3) publication in languages other than French or English.

Data extraction. A standard data extraction form was used to collect the relevant information from the included studies. Extracted data included year of publication, country, study design, source of funding, sample size, SLE definition, and $\mathrm{ON}$ definition. The risk factors evaluated were grouped into 4 categories: (1) those related to CS [history of CS use, current CS use (yes/no), mean daily dose of CS, highest dose of CS (mg/day and $\mathrm{g} / \mathrm{month}$ ), total cumulative CS dose, Cushingoid appearance]; (2) those related to clinical manifestations [disease activity, arthritis, neuropsychiatric SLE, Raynaud phenomenon (RP), vasculitis, serositis, gastrointestinal (GI) involvement, hypertension (HTN), oral ulcers, renal disease, alopecia]; (3) those related to laboratory results [lupus anticoagulant (LAC), anticardiolipin antibodies (aCL) IgM and $\mathrm{IgG}$, anti- $\beta_{2}$-glycoprotein] I antibody; and (4) those related to treatment other than CS (antimalarial, immunosuppressive agents).

Quality assessment. Because no RCT were identified, the quality of each study was graded according to the Newcastle-Ottawa scale for nonrandomized studies (NOS $)^{13}$, a tool developed to assess the quality of that type of study. A maximum of 9 stars could be attributed to each study, with a higher number of stars indicating a higher quality. In addition, the quality of the evidence per risk factor was evaluated according to GRADE approach $^{14}$, which encompasses 8 major domains: risk of bias, directness of evidence, inconsistency, imprecision, publication bias, large effect, dose response, and opposing residual confounding.

Statistical analysis. For each included study and for each relevant outcome, we extracted or computed the necessary information. For binary outcomes (e.g., renal disease), we obtained OR with corresponding standard errors. When OR were not given directly, they were computed from raw data or other given information (e.g., risk ratios). For continuous outcomes (e.g., highest dose of CS), we obtained mean difference with standard error. Standard errors of the mean difference (when not given directly) were computed from other information (e.g., SD, CI, and p values). Results were then pooled using the DerSimonian-Laird random effects method; OR were pooled on the log scale ${ }^{15}$. For study level and pooled estimates, $95 \%$ CI were reported. Statistical heterogeneity was quantified using the $\mathrm{I}^{2}$ statistic ${ }^{16}$.

\section{RESULTS}

Literature search. After removing duplicate results, 370 references were identified. Of these studies, 304 records were excluded after initial review of titles and abstracts. After evaluation of the full-length paper of the remaining 66 articles, 50 studies were included in the final analysis (Figure 1). The majority of full-text articles were excluded because they did not include a comparator group (patients with SLE without $\mathrm{ON}$ ) or because of lack of extractable data.

Study characteristics. The details of the study characteristics are displayed in Supplementary Table 1, available with the online version of this article. No RCT was identified. Almost all included studies were the case-control type (46 of 50 studies). The NOS scores varied between 3 and 8 , with a mean score \pm SD of $5.72 \pm 1.06$ and a median score of 6 . One article had a score of 8,10 articles had a score of 7, 18 articles had a score of 6 , and 18 articles had a score of 5 or lower. The quality of the body of evidence for each risk factor was assessed as low to very low because of risk of bias, inconsistency, and imprecision for most risk factors (Table 1).

Risk factors related to CS. Several approaches were taken to evaluate the risk associated with CS (Figure 2). Three studies examined current use (yes/no) for patients with SLE ${ }^{17,18,19}$. One found a statistically significant higher risk of $\mathrm{ON}$ in

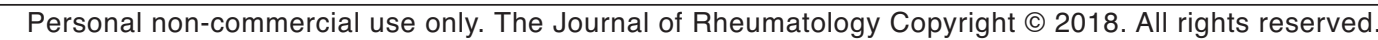




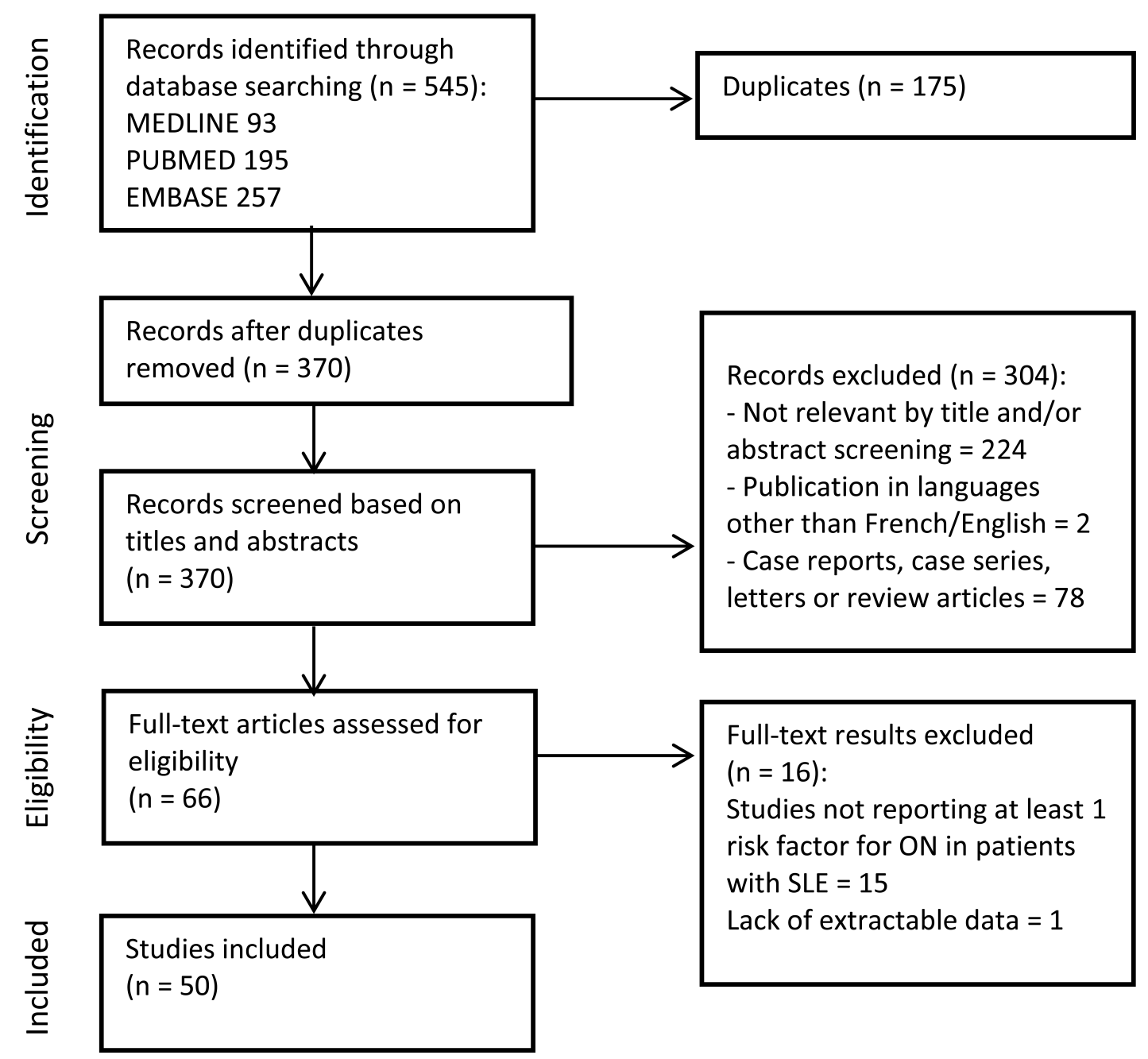

Figure 1. Flow diagram of the literature search process, including reasons for exclusions. ON: osteonecrosis; SLE: systemic lupus erythematosus.

patients using CS compared to those without CS use, whereas the other 2 studies did not. Although not statistically significant, a trend toward increased risk of ON was observed when the 3 studies were combined. One study looked at the history of CS use (yes/no) and did not find an association with $\mathrm{ON}^{20}$. Combining the results of 23 studies $3,17,18,21-40$, total cumulative dose of CS was higher in patients with SLE who had ON than in patients with SLE without ON (mean difference $3.71 \mathrm{~g}, 95 \%$ CI 0.79-6.64). The average daily dose $^{3,18,29,30,32,34,35,37,38,40-46}$ and the highest daily dose ${ }^{1-3,17,18,22,24-28,34,38-40,42,46-51}$ were also higher in patients who presented with ON (mean difference $3.19 \mathrm{mg} /$ day, $95 \%$ CI 1.18-5.21, and mean difference $6.41 \mathrm{mg} / \mathrm{day}, 95 \% \mathrm{CI}$ 2.94-9.88, respectively). The highest cumulative CS dose received in 1 month was, however, not statistically different between patients with SLE with or without $\mathrm{ON}^{30,31,32,35}$. The use of pulse therapy has been studied in 17 articles $^{2,3,20,28,30,32,35,41,43,45,48,52-57}$ and was associated with ON (OR 1.79, 95\% CI 1.31-2.46). Cushingoid appearance was also a risk factor associated with ON (OR $3.66,95 \%$ CI 2.20-6.10) 1 1,3,17,27,30,32,40,46,52,54,58.

Risk factors related to clinical manifestations. Significant risk factors associated with ON (Figure 3) were arthritis (OR

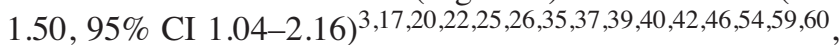
neuropsychiatric manifestations of SLE (OR 2.03, 95\% CI $1.52-2.72)^{17,20,21,22,25,26,30,32,35-40,42,46,47,48,52,53,55,57,59-62}$, RP (OR $1.28,95 \%$ CI $1.06-1.54)^{3,17,20-22,24-27,30,32,35,36,37,}$ $39-41,44,46-48,52,57,58,60$, vasculitis (OR $2.13,95 \%$ CI $1.48-3.07) 1,17,22,25,27,30,32,35,36,40,46,52,54,58,61$, and HTN (OR 1.76, 95\% CI $1.49-2.08)^{3,19,20,22,30,32,35,37,38,40,42,45,48,53,61}$. There was also a higher risk of ON in patients with SLE presenting with serositis, including pericarditis and/or pleuritis (OR 1.68, 95\% CI 1.24-2.26) 22,25,30,32,35,37, $40,43,54,59-61$. Renal disease, defined as proteinuria of $>0.5$ $\mathrm{g} /$ day and/or active urinary sediment and/or creatinine $>1.4$ $\mathrm{mg} / \mathrm{dl}(123.2 \mu \mathrm{mol} / \mathrm{l})$ and/or biopsy-proven lupus nephritis, was also a risk factor for ON (OR $1.70,95 \% \mathrm{CI}$ $1.32-2.19)^{3,17,19,20,22,25,26,30,32,35,36,37-40,43,46-48,53,54,57,59-61)}$. 
Table 1. Summary of the evidence quality grading using GRADE.

\begin{tabular}{|c|c|c|}
\hline Risk Factor & $\begin{array}{l}\text { No. Studies } \\
\text { Included }\end{array}$ & $\begin{array}{c}\text { Quality of } \\
\text { Evidence (GRADE) }\end{array}$ \\
\hline History of CS use & 1 & $\begin{array}{l}\otimes 000 \\
\text { VERY LOW }\end{array}$ \\
\hline Current CS use & 3 & $\begin{array}{c}\otimes \otimes \bigcirc \bigcirc \\
\text { LOW }\end{array}$ \\
\hline Average daily dose of CS & 16 & $\begin{array}{c}\otimes \otimes \bigcirc \bigcirc \\
\text { LOW }\end{array}$ \\
\hline Highest dose of CS (mg/day) & 21 & $\underset{\text { LOW }}{\otimes \otimes \bigcirc \bigcirc}$ \\
\hline Highest CS dose (g/month) & 4 & $\begin{array}{l}\otimes 000 \\
\text { VERY LOW }\end{array}$ \\
\hline Total cumulative CS dose & 23 & $\underset{\text { LOW }}{\otimes \otimes \bigcirc \bigcirc}$ \\
\hline Pulse of CS & 17 & $\begin{array}{c}\otimes \otimes \bigcirc \bigcirc \\
\text { LOW }\end{array}$ \\
\hline Cushingoid appearance & 11 & $\begin{array}{c}\otimes \otimes \bigcirc \bigcirc \\
\text { LOW }\end{array}$ \\
\hline Arthritis & 15 & $\underset{\text { LOW }}{\otimes \otimes \bigcirc \bigcirc}$ \\
\hline Neuropsychiatric SLE & 24 & $\begin{array}{c}\otimes \otimes \bigcirc \bigcirc \\
\text { LOW }\end{array}$ \\
\hline Raynaud phenomenon & 27 & $\begin{array}{c}\otimes \otimes \bigcirc \bigcirc \\
\text { LOW }\end{array}$ \\
\hline Vasculitis & 15 & $\begin{array}{c}\otimes \otimes \bigcirc \bigcirc \\
\text { LOW }\end{array}$ \\
\hline Serositis & 12 & $\underset{\text { LOW }}{\otimes \otimes \bigcirc \bigcirc}$ \\
\hline Gastrointestinal involvement & 1 & $\begin{array}{l}\otimes 000 \\
\text { VERY LOW }\end{array}$ \\
\hline Hypertension & 15 & $\begin{array}{c}\otimes \otimes \bigcirc \bigcirc \\
\text { LOW }\end{array}$ \\
\hline Oral ulcers & 11 & $\begin{array}{c}\otimes \otimes \bigcirc \bigcirc \\
\text { LOW }\end{array}$ \\
\hline Renal disease & 25 & $\begin{array}{c}\otimes \otimes \bigcirc \bigcirc \\
\text { LOW }\end{array}$ \\
\hline Alopecia & 9 & $\begin{array}{c}\otimes \otimes \bigcirc \bigcirc \\
\text { LOW }\end{array}$ \\
\hline SLEDAI $>8$ in the previous year & 1 & $\begin{array}{c}\otimes \bigcirc \bigcirc \bigcirc \\
\text { VERY LOW }\end{array}$ \\
\hline Anticardiolipin antibodies IgM & 8 & $\begin{array}{l}\otimes 000 \\
\text { VERY LOW }\end{array}$ \\
\hline Anticardiolipin antibodies $\operatorname{IgG}$ & 10 & $\begin{array}{l}\otimes 000 \\
\text { VERY LOW }\end{array}$ \\
\hline Lupus anticoagulant & 11 & $\begin{array}{c}\otimes \otimes \bigcirc \bigcirc \\
\text { LOW }\end{array}$ \\
\hline Antimalarial & 14 & $\begin{array}{c}\otimes \otimes \bigcirc \bigcirc \\
\text { LOW }\end{array}$ \\
\hline Mixed immunosuppressive agents & 10 & $\begin{array}{c}\otimes \otimes \bigcirc \bigcirc \\
\text { LOW }\end{array}$ \\
\hline Cyclophosphamide use & 7 & $\begin{array}{c}\otimes \otimes \bigcirc \bigcirc \\
\text { LOW }\end{array}$ \\
\hline Azathioprine use & 8 & $\begin{array}{c}\otimes \otimes \bigcirc \bigcirc \\
\text { LOW }\end{array}$ \\
\hline Mycophenolate mofetil use & 4 & $\begin{array}{l}\otimes \bigcirc 00 \\
\text { VERY LOW }\end{array}$ \\
\hline Methotrexate use & 3 & $\begin{array}{c}\otimes \bigcirc 00 \\
\text { VERY LOW }\end{array}$ \\
\hline
\end{tabular}

GRADE: Grading of Recommendations, Assessment, Development, and Evaluation; CS: corticosteroids; SLE: systemic lupus erythematosus; SLEDAI: SLE Disease Activity Index.
One study ${ }^{27}$ evaluated disease activity as a risk factor for ON in patients with SLE and found that a Systemic Lupus Erythematosus Disease Activity Index (SLEDAI) $>8$ in the previous year statistically increases the risk of ON (OR 6.78, 95\% CI 1.05-43.66). Alopecia $25,30,32,35,37,40,43,44,60$ and oral ulcers $^{22,25,26,30,32,35,40,43,46,59,60}$ did not show a significant association with ON. Only 1 study evaluated GI involvement as a risk factor for $\mathrm{ON}$ in patients with $\mathrm{SLE}^{61}$, and it did not find a statistically significant association.

Risk factors related to laboratory results. Overall, studies that investigated the association between aCL and $\mathrm{ON}$ did not find a significant association (Figure 4) ${ }^{3,17,20,26,57}$. In studies that looked at aCL subtypes, aCL IgM were more often positive in patients with SLE who had ON compared to

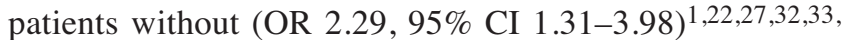
$35,36,59$; however, aCL $\operatorname{IgG} 1,22,27,30,32,33,35,36,38,59$ and $\mathrm{LAC}^{22,26,27,30,32,33,35,42,48,57,59}$ were not associated with $\mathrm{ON}$. The 2 studies that evaluated the association between anti- $\mathrm{B}_{2}$-glycoprotein I antibody and $\mathrm{ON}$ found no associ$\operatorname{ation}^{30,63}$. Interestingly, 1 study found an association between vitamin $\mathrm{D}$ deficiency and $\mathrm{ON}^{19}$.

Risk factors related to treatment other than CS. The use of antimalarials $3,17,20,22,26,27,38,42,53,57,59,61,62,64$ showed no effect on the risk of ON (Figure 5). The use of at least 1 immunosuppressive agent (including methotrexate, azathioprine, cyclophosphamide, cyclosporine, and mycophenolate mofetil) was associated with an increased risk of ON (OR 1.87, 95\% CI 1.17-2.98) $)^{3,17,27,35,48,52,53,54,57,61}$. When studied independently, cyclophosphamide was the only immunosuppressive agent associated with the development of ON (OR 2.98, 95\%

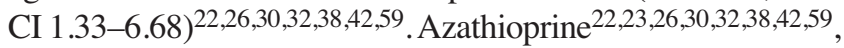
methotrexate $26,53,59$, and mycophenolate mofetil ${ }^{22,26,30,38}$ were not associated with a higher risk of $\mathrm{ON}$.

\section{DISCUSSION}

The objective of our study was to determine the risk factors associated with $\mathrm{ON}$, an important complication affecting patients with SLE. Our systematic review of the literature revealed that studies were heterogeneous in terms of design and quality. Nevertheless, some important points emerged.

CS are a risk factor that may be associated with ON. The average daily dose of CS, highest dose of CS, total cumulative CS dose, pulse therapy, and Cushingoid appearance were all associated with ON. However, the quality of this evidence was low to very low because of the high risk of bias and often inconsistency across studies, and therefore strong conclusions cannot be made. Although 2 of the 3 studies that investigated the current use of CS and the study that examined the history of CS use did not show a statistically significant association with ON, a clear tendency in favor of an association was observed.

This is in agreement with the observation that $\mathrm{ON}$ is rarely observed in patients with SLE who did not receive $\mathrm{CS}^{17}$. Also, empirical evidence suggests that $\mathrm{ON}$ is closely associated with

Personal non-commercial use only. The Journal of Rheumatology Copyright @ 2018 . All rights reserved. 
Odds Ratio

Study or Subgroup Weight IV, Random, $95 \% \mathrm{CI}$ 1.19.1 History of CS us

$\begin{array}{lll}\text { Cozen } 1998 & 100.0 \% & 1.72[0.58,5.09\end{array}$
Subtotal $(95 \% \mathrm{CI}) \quad 100.0 \% \quad 1.72[0.58,5.09]$

Heterogeneity. Not applicable

Test for overall effect: $Z=0.98(P=0.33)$

\subsubsection{Current CS use}

Gladman 2001

Gurion 2013

Gurion 2015

Subtotal $(95 \% \mathrm{CI}) \quad 100.0 \% \quad 2.98[0.79,11.32]$

Heterogeneity. $\mathrm{Tau}^{2}=0.98 ; \mathrm{Chi}^{2}=6.92, \mathrm{df}=2(\mathrm{P}=0.03) ; \mathrm{I}^{2}=71 \%$

Test for overall effect: $Z=1.61(\mathrm{P}=0.11$

Test for subgroup differences: $\mathrm{Chi}^{2}=0.39, \mathrm{df}=1\left(\mathrm{P}=0.53 \mathrm{)}, \mathrm{I}^{2}=0 \%\right.$
Odds Ratio

IV, Random, $95 \% \mathrm{CI}$

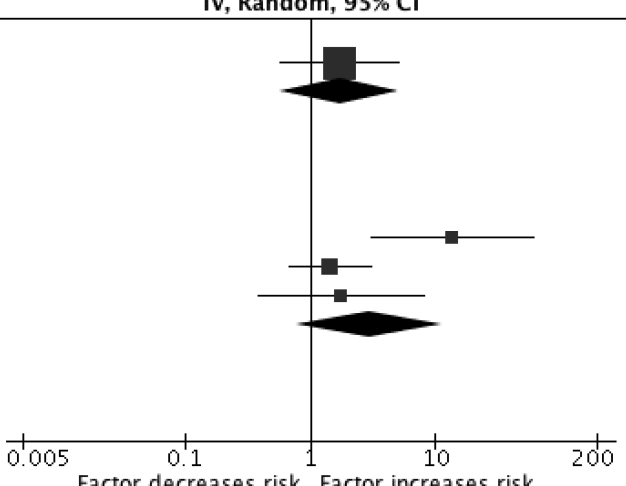

B

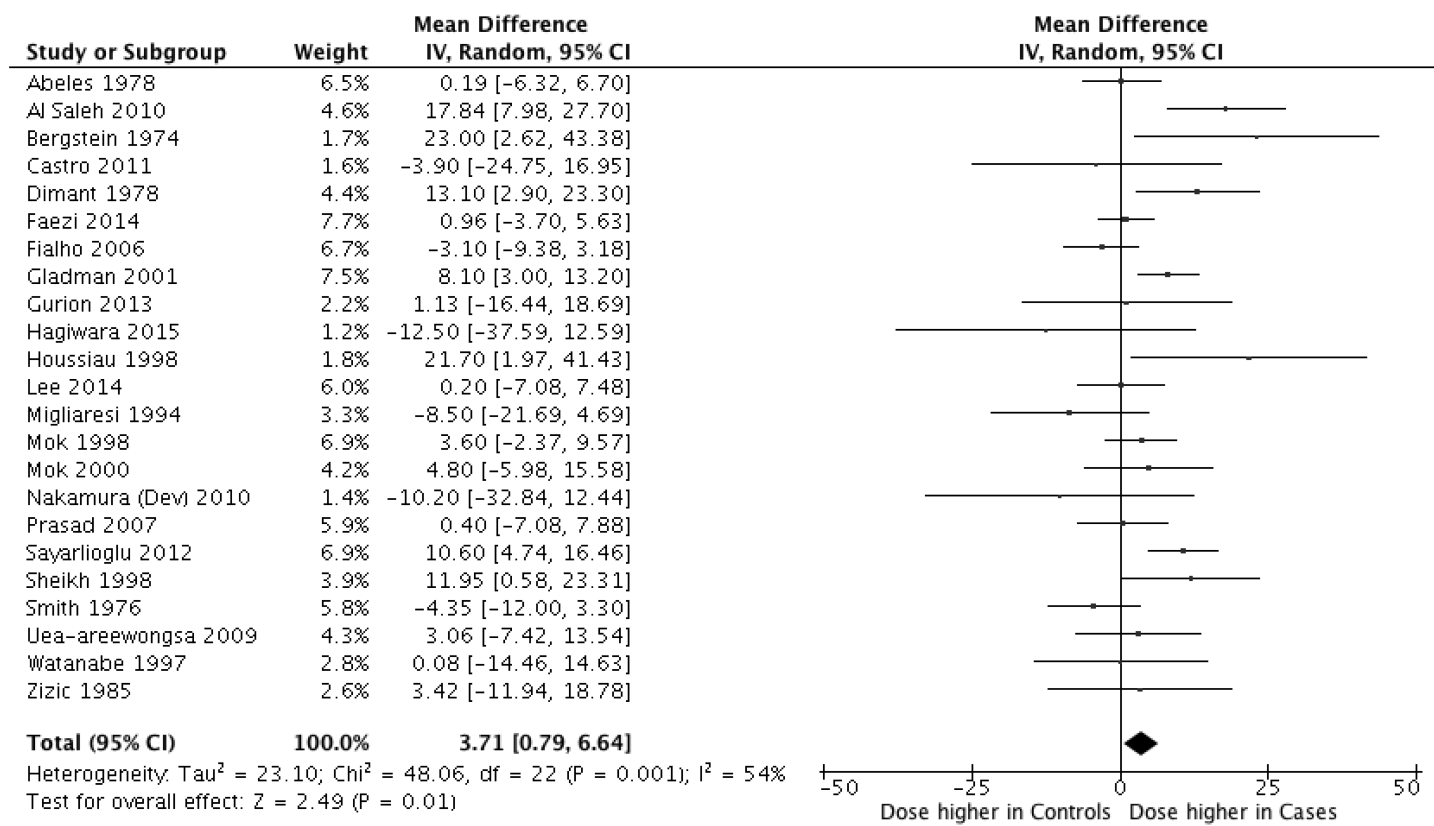

Figure 2A-B. Forest plots for risk factors associated with corticosteroid use: A. CS use; B. Total cumulative CS dose (g). CS: corticosteroids.

the use of high-dose CS early in the course of SLE, especially in patients who develop Cushingoid appearance ${ }^{1,17,32,40,54,65}$. However, 1 study of 144 patients followed by periodic MRI (hips and knees) for a minimum of 10 years found no new lesion development in patients receiving a low or medium CS dose $(<30 \mathrm{mg} \text { /day of prednisone })^{34}$.

Although the effect of CS on ON seems to be clearly established, the pathophysiology is not fully understood. It has been hypothesized that chronic CS use promotes intraosseous adipocyte hypertrophy and fat conversion of red marrow, leading to increased bone marrow pressure, which compromises intraosseous perfusion ${ }^{8}$. Another postulated mechanism is that CS alter lipid metabolism, leading to fat microemboli in subchondral vessels ${ }^{8}$.
The higher prevalence of ON in patients with SLE compared to other diseases requiring CS therapy suggests that additional SLE-specific risk factors may be involved ${ }^{9}$. Indeed, our systematic review identified additional possible risk factors for ON in patients with SLE; however, not all data regarding these risk factors were concordant.

Although antimalarials may have antithrombotic ${ }^{66}$ and lipid-lowering properties ${ }^{67}$, our review showed that using antimalarials may have little to no effect on the risk of $\mathrm{ON}$ in patients with SLE.

ON has been identified in patients with primary antiphospholipid syndrome without previous CS therapy, suggesting a role for antiphospholipid antibodies (aPL) in the pathophysiology of $\mathrm{ON}^{68}$. Indeed, it is reasonable to think that these 


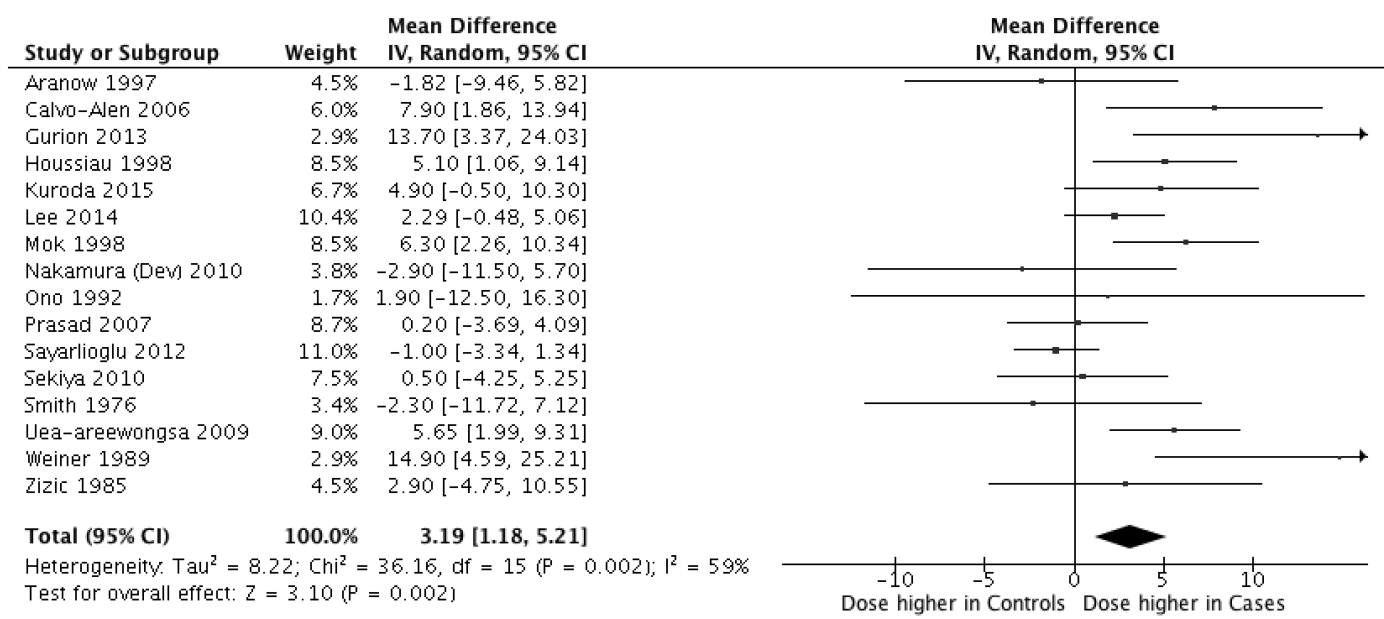

D

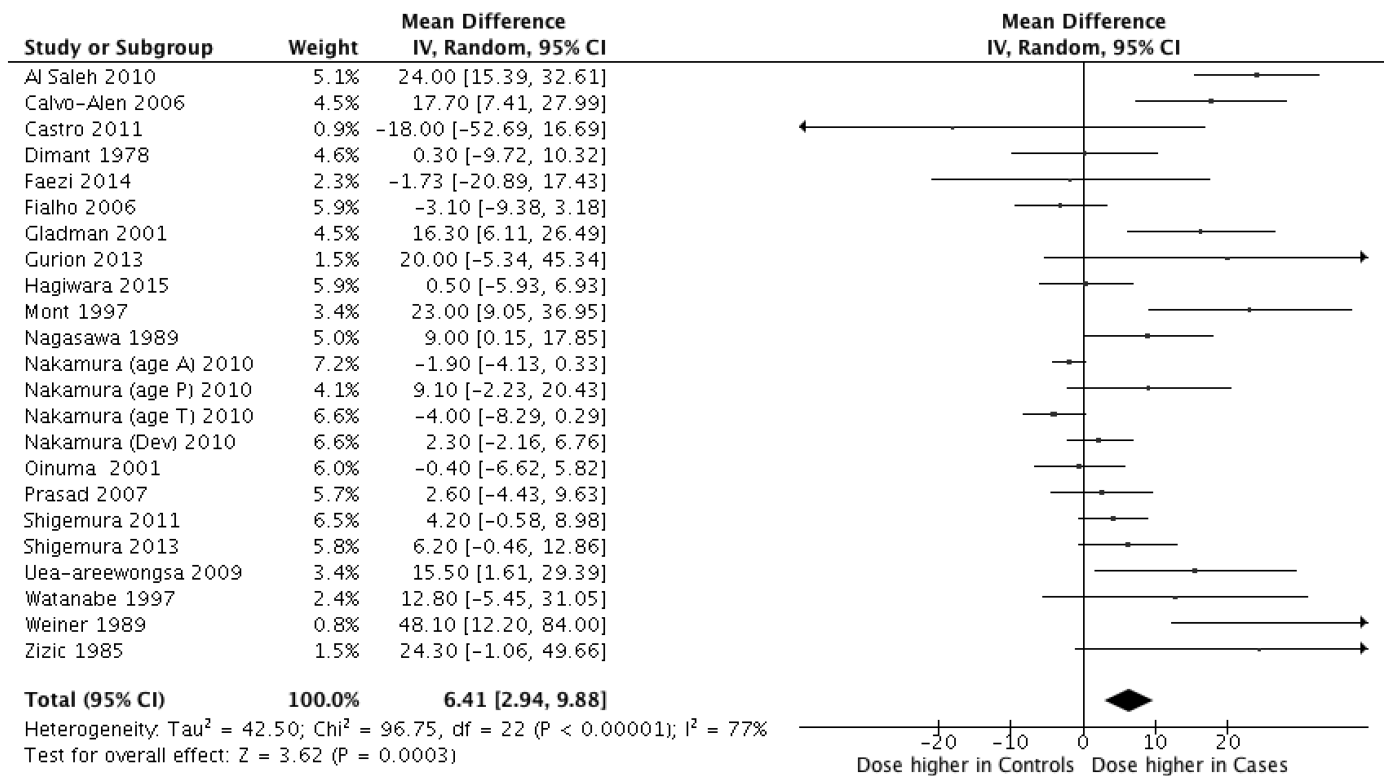

E

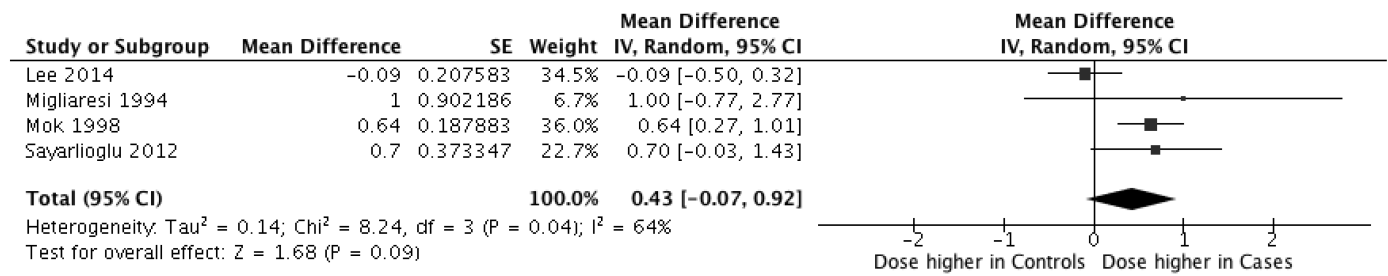

Figure 2C-E. Forest plots for risk factors associated with corticosteroid use: C. Average daily CS dose (mg/day); D. Highest $\mathrm{CS}$ dose (mg/day); E. Highest CS dose (g/month). CS: corticosteroids.

antibodies may induce a hypercoagulable state that could cause vessel thrombosis and lead to bone ischemia and necrosis. The various studies on the risk of $\mathrm{ON}$ associated with aPL in SLE showed conflicting data, and the pooled result showed that there may only be an association with aCL of the IgM subtype, but this is uncertain. This observation is certainly difficult to explain, but is consistent with another metaanalysis published on this subject that found the same

Personal non-commercial use only. The Journal of Rheumatology Copyright @ 2018 . All rights reserved. 


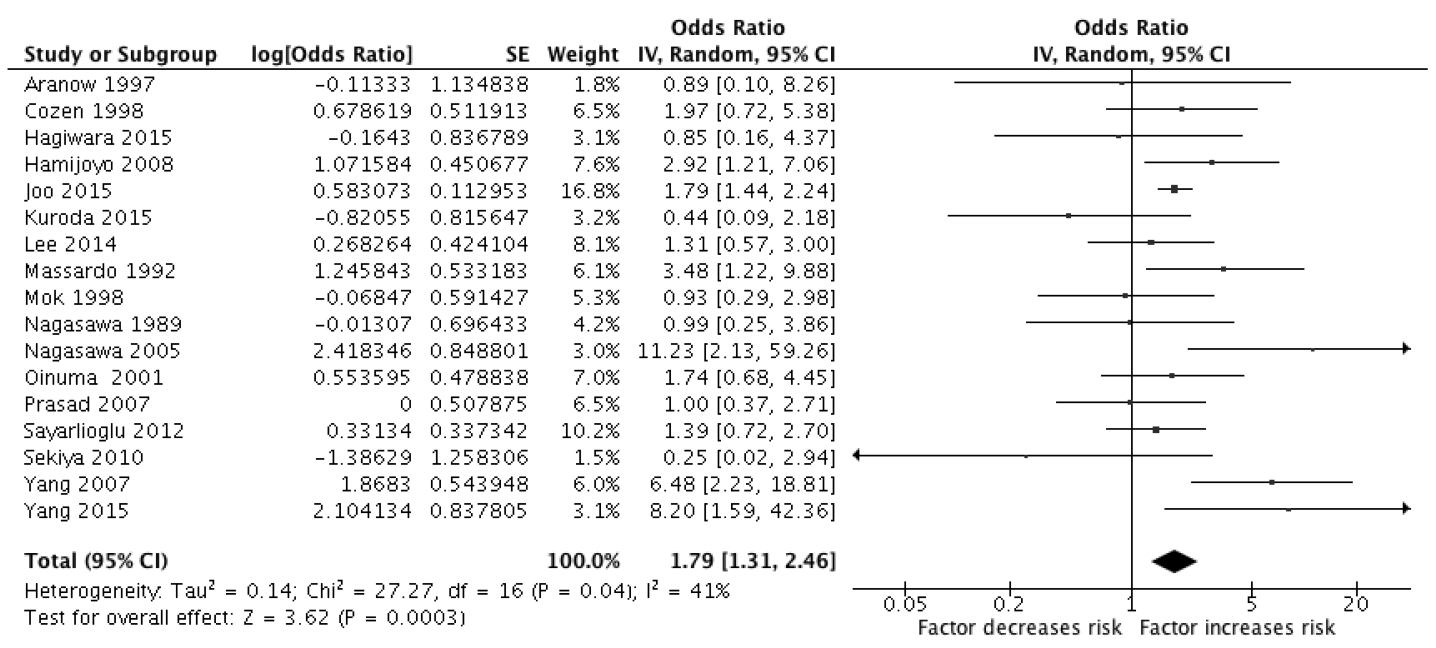

G

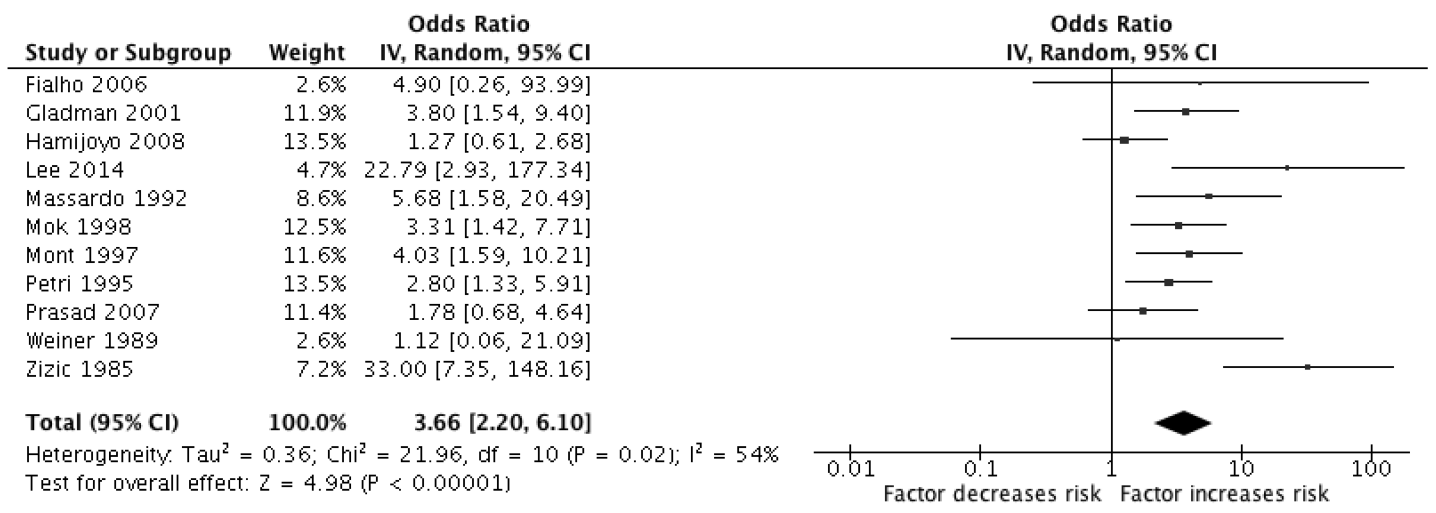

Figure $2 F-G$. Forest plots for risk factors associated with corticosteroid use: F. Corticosteroid pulse; G. Cushingoid appearance.

result ${ }^{69}$. Another one ${ }^{70}$ did not find a strong correlation between aPL and the occurrence of ON. Thus, the true character of the association between aPL and ON in SLE is not clear and seems to be, at best, weak.

It could be postulated that immunosuppressive agents could lead to $\mathrm{ON}$ by a direct cytotoxic effect on osteoblasts and osteoclasts. In fact, some authors found that immunosuppressive therapy is a risk factor for $\mathrm{ON}^{17,22,30,32,42,57}$. Conversely, these agents could be surrogates for disease activity, which could be a risk for ON. Also, their use likely clusters with CS but their use could also be steroid-sparing. In most of these studies, immunosuppressive therapy was not studied as an independent risk factor. However, 1 study found that cytotoxic drug use remained a significant risk factor for the occurrence of ON, even after adjusting for the use of CS and other treatments ${ }^{42}$. In our study, no difference was observed between $\mathrm{ON}$ cases and controls regarding disease activity. Similarly, another article found that cytotoxic drugs remain a significant risk factor for $\mathrm{ON}$ in multivariate analysis (OR 2.7, 95\% CI 1.02-8.8; $\mathrm{p}=0.046)^{17}$.
Our review provides a comprehensive picture of the risk factors of ON in patients with SLE. It was conducted as part of the development of Canadian clinical practice recommendations for the diagnosis and monitoring of patients with SLE, which are the first, to our knowledge, to use the GRADE methodology for SLE and are endorsed by different SLE associations across Canada. The aim of our review was to identify subgroups of patients with SLE at risk of ON, and to optimally monitor them for this debilitating complication. The strength of this metaanalysis is that we used a systematic approach and established a quality of evidence for each risk factor with the GRADE approach. However, some limitations must be identified. First, only a few included studies controlled for confounders and provided adjusted results. This may help explain the notable heterogeneity for some outcomes. We reported adjusted results whenever possible, because many risk factors for ON may be codependent. Second, all studies included in this review had an observational design, and therefore causality cannot be inferred. Also, the different diagnostic methods of ON (with varying

Personal non-commercial use only. The Journal of Rheumatology Copyright ( $)$ 2018. All rights reserved. 
A

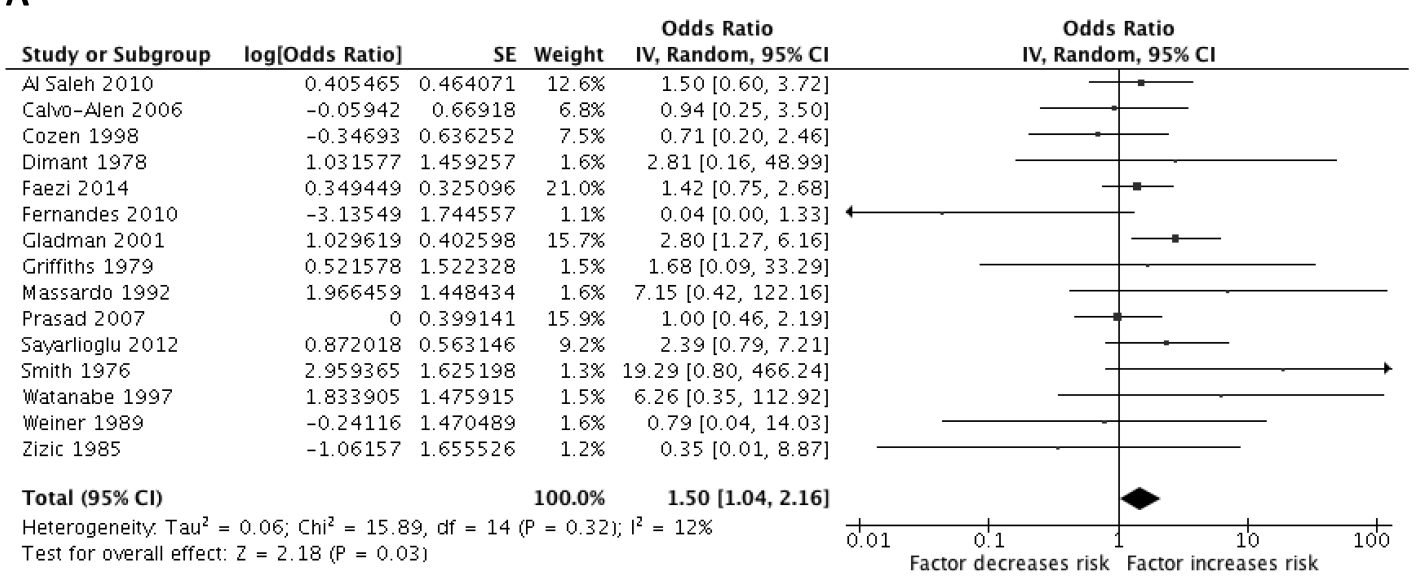

B

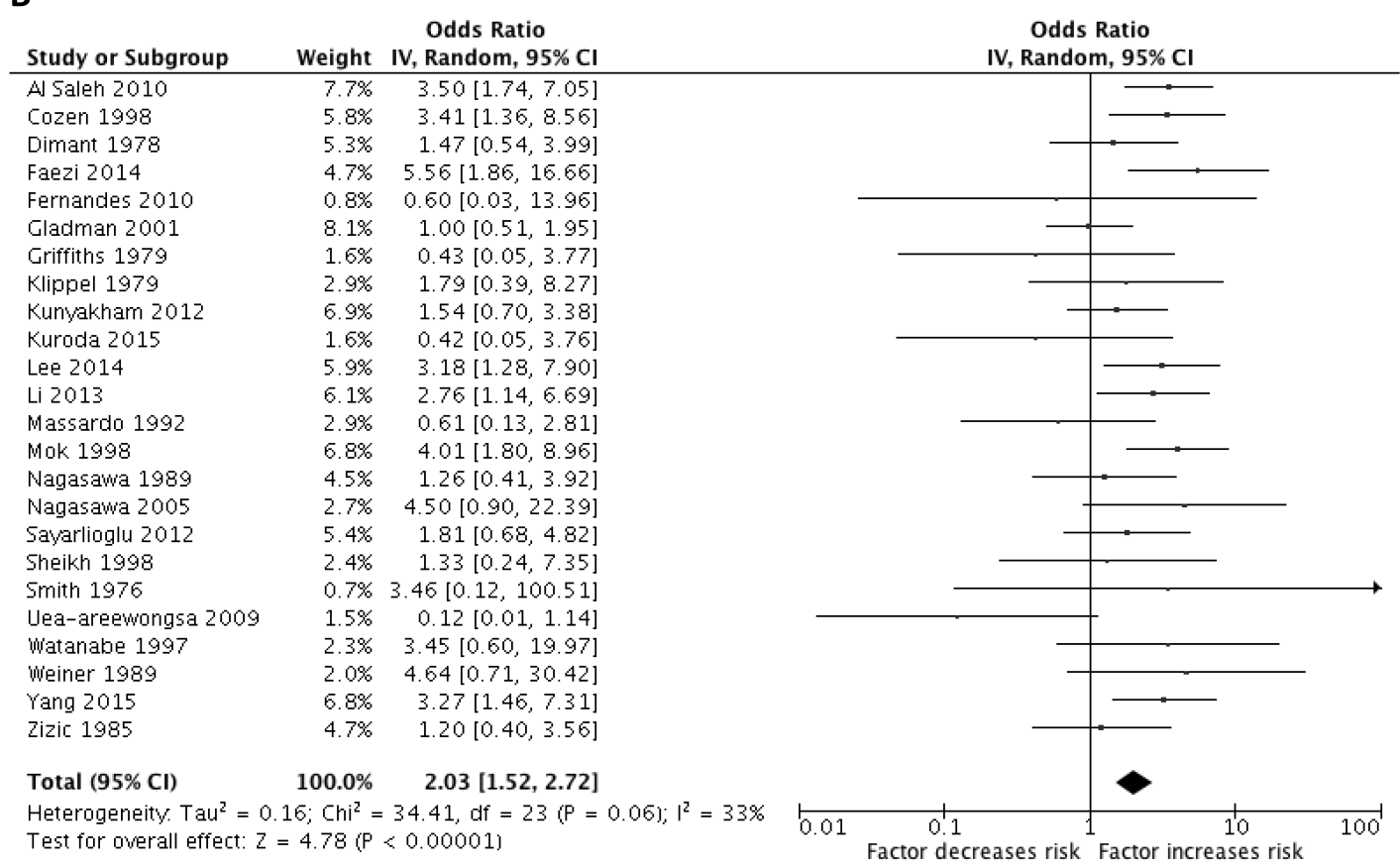

Figure 3A-B. Forest plots for clinical manifestations of SLE: A. Arthritis; B. Neuropsychiatric SLE. SLE: systemic lupus erythematosus.

sensitivity) used in the included studies are a source of heterogeneity. Finally, although some studies were graded as good quality according to the NOS scale, the quality of evidence for the risk factors was low to very low based on GRADE. This limits our ability to draw strong conclusions concerning some risk factors.

Based on the published literature, CS may be a strong risk factor associated with ON in patients with SLE. Other risk factors, such as arthritis, neuropsychiatric manifestations of SLE, vasculitis, hypertension, serositis, and renal disease may be moderately associated with ON, and a SLEDAI score $>8$ may be strongly associated with ON, but this is still uncertain due to the very low quality of evidence. Results of this review may be considered by clinicians in their assessment of the risk of ON in patients with SLE. A careful medical history should be obtained, including information about CS use. Physicians should maintain a high index of suspicion for $\mathrm{ON}$ in patients with SLE, especially in the presence of known risk factor such as the use of CS. Patients should be educated on the presenting symptoms of ON (progressive or sudden deep joint pain worse with movements). We suggest adopting a preventive strategy with a judicious use of CS.

Personal non-commercial use only. The Journal of Rheumatology Copyright (c) 2018. All rights reserved. 


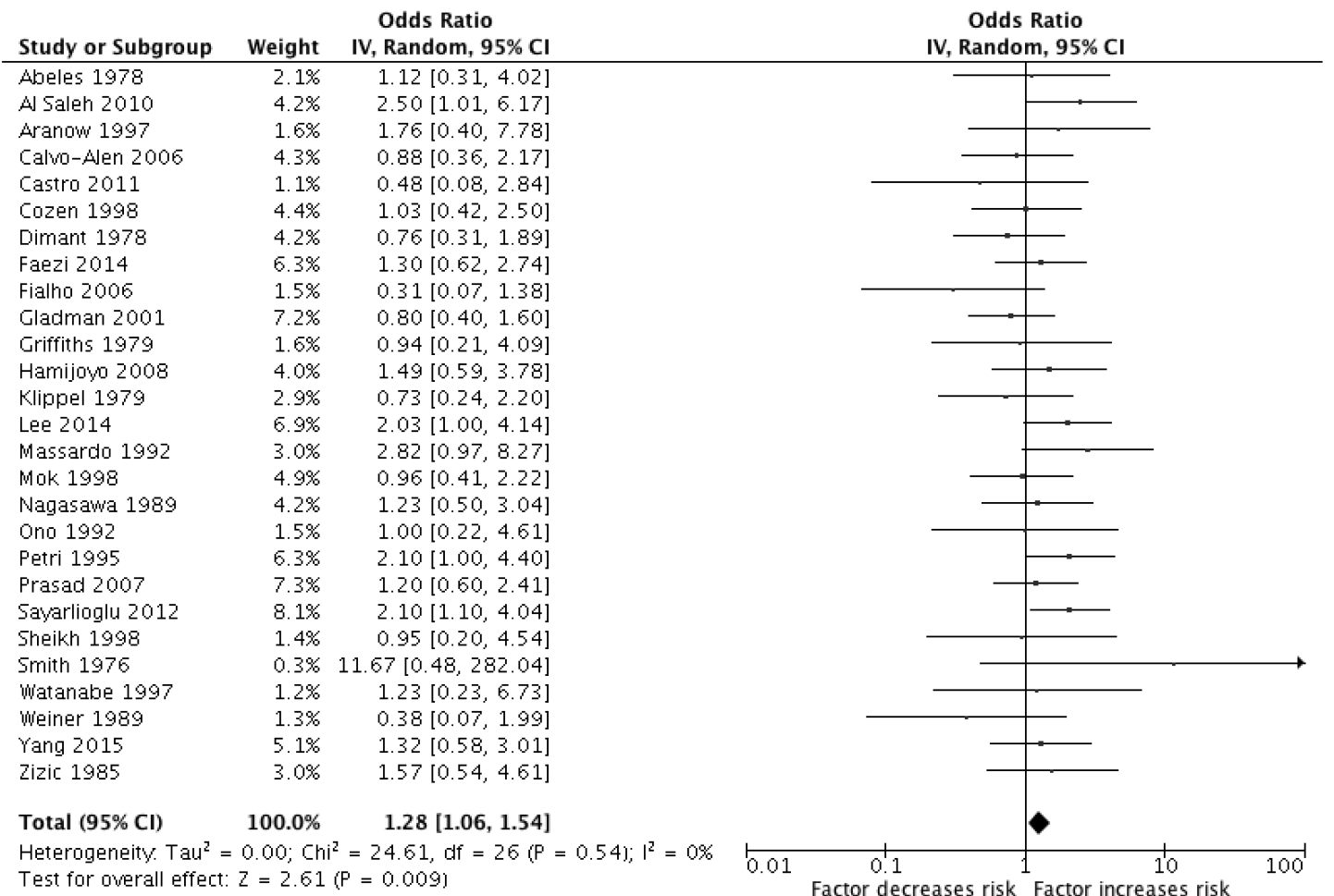

D

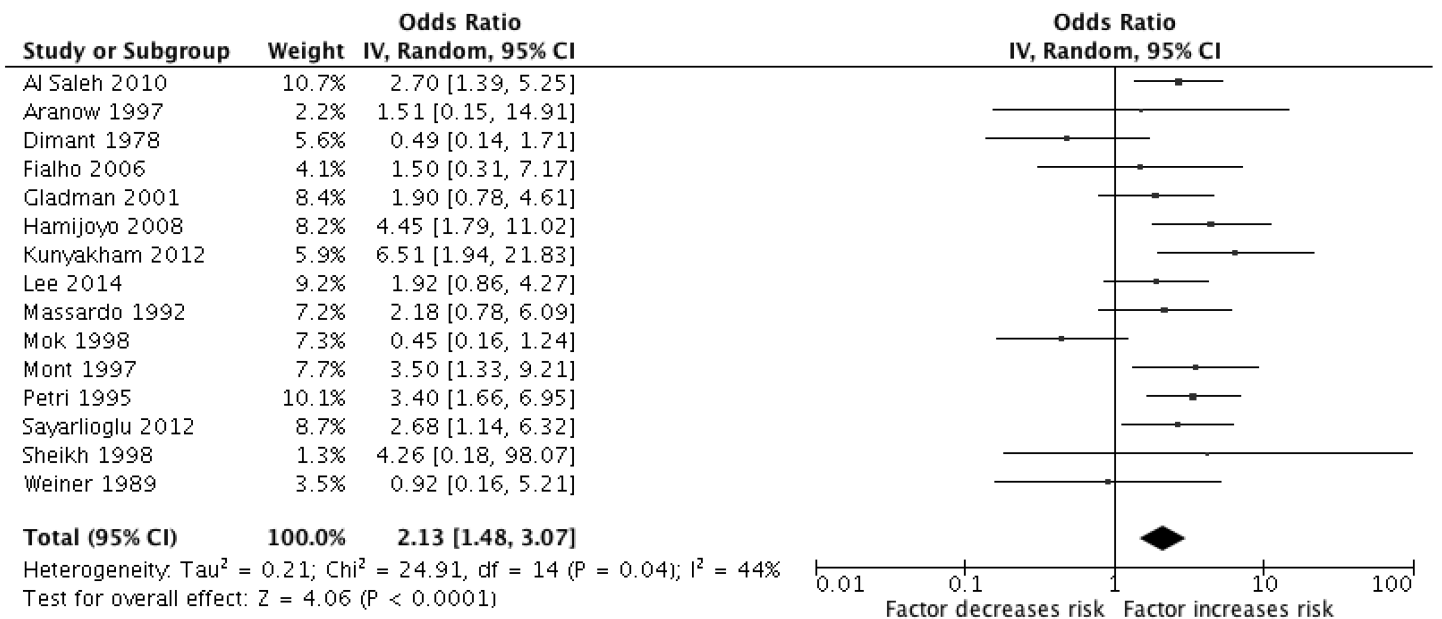

Figure 3C-D. Forest plots for clinical manifestations of SLE: C. Raynaud phenomenon; D. Vasculitis. SLE: systemic lupus erythematosus.

\section{ACKNOWLEDGMENT}

We thank all the members of the Canadian SLE working group. We also thank Isabelle Théotol for her assistance in the literature search.

\section{ONLINE SUPPLEMENT}

Supplementary material accompanies the online version of this article.

\section{REFERENCES}

1. Mont MA, Glueck CJ, Pacheco IH, Wang P, Hungerford DS, Petri M. Risk factors for osteonecrosis in systemic lupus erythematosus. J Rheumatol 1997;24:654-62.
2. Oinuma K, Harada Y, Nawata Y, Takabayashi K, Abe I, Kamikawa $\mathrm{K}$, et al. Osteonecrosis in patients with systemic lupus erythematosus develops very early after starting high dose corticosteroid treatment. Ann Rheum Dis 2001;60:1145-8.

3. Prasad R, Ibanez D, Gladman D, Urowitz M. The role of non-corticosteroid related factors in osteonecrosis $(\mathrm{ON})$ in systemic lupus erythematosus: a nested case-control study of inception patients. Lupus 2007;16:157-62.

4. Gladman DD, Chaudhry-Ahluwalia V, Ibañez D, Bogoch E, Urowitz MB. Outcomes of symptomatic osteonecrosis in 95 patients with systemic lupus erythematosus. J Rheumatol 2001;28:2226-9.

5. Ghaleb RM, Omar GM, Ibrahim MA. Avascular necrosis of bone in 


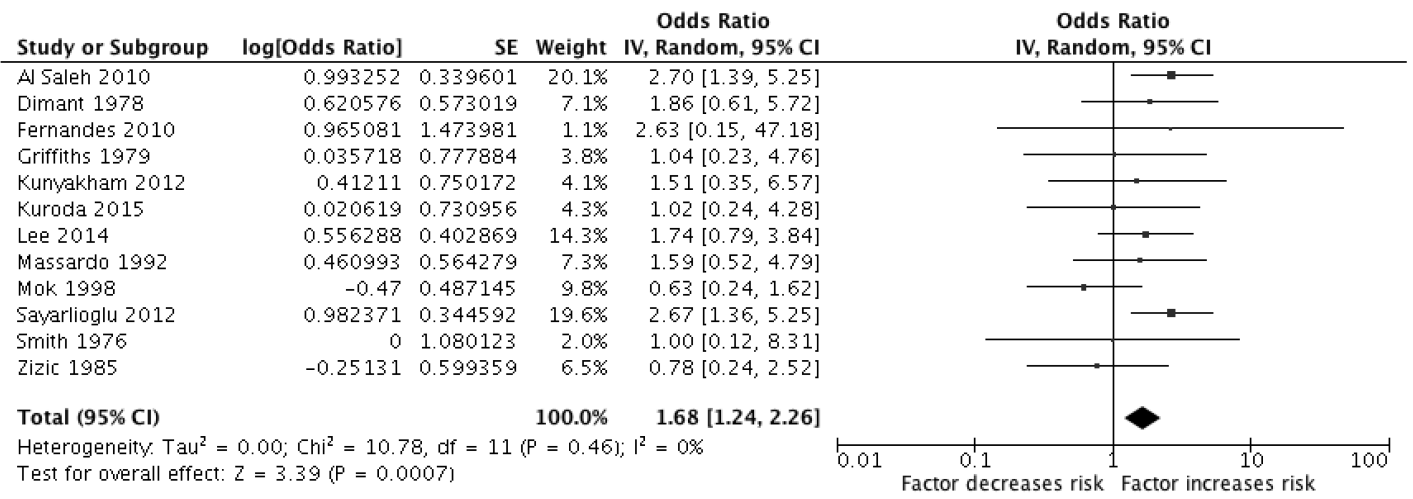

$\mathbf{F}$

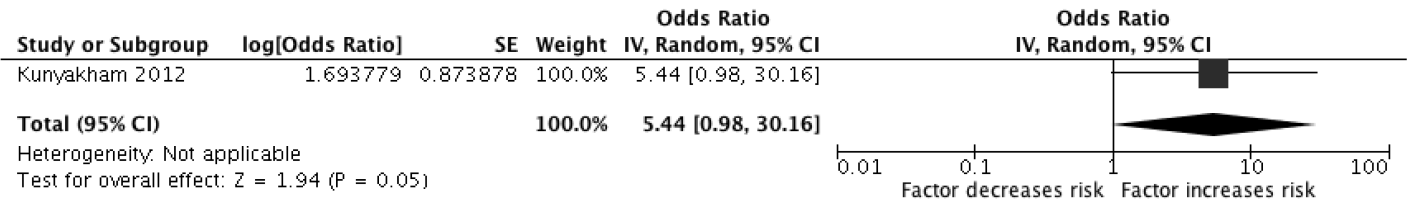

G

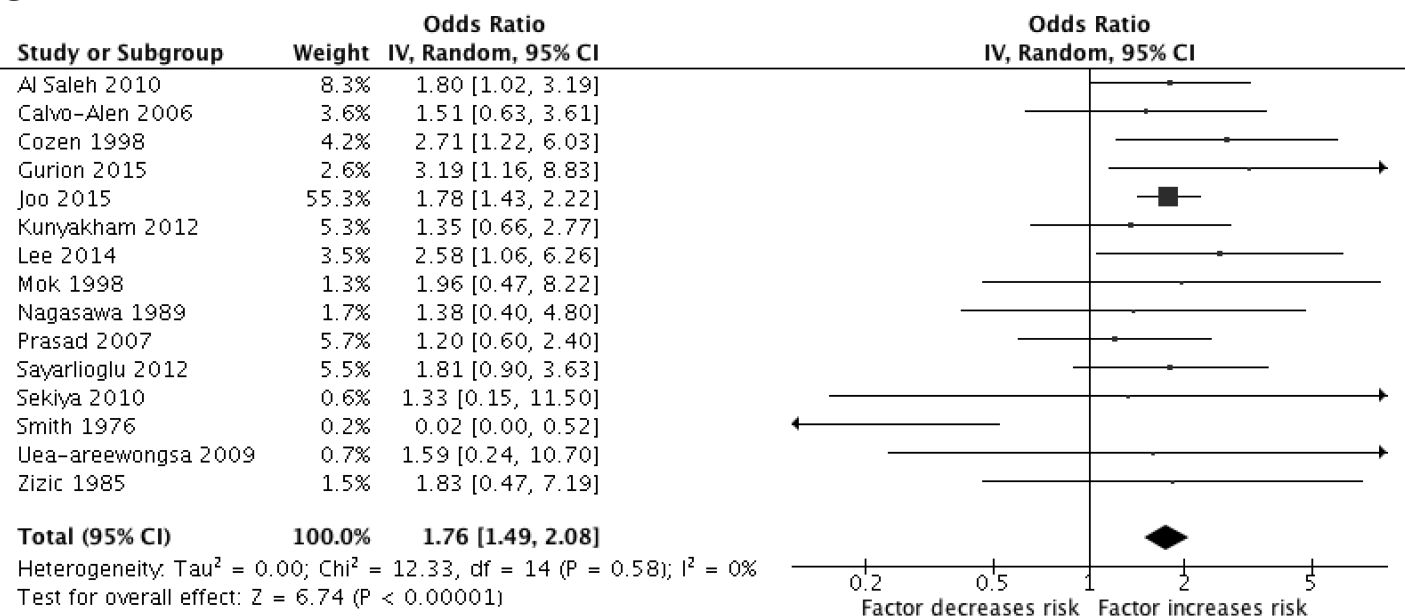

H

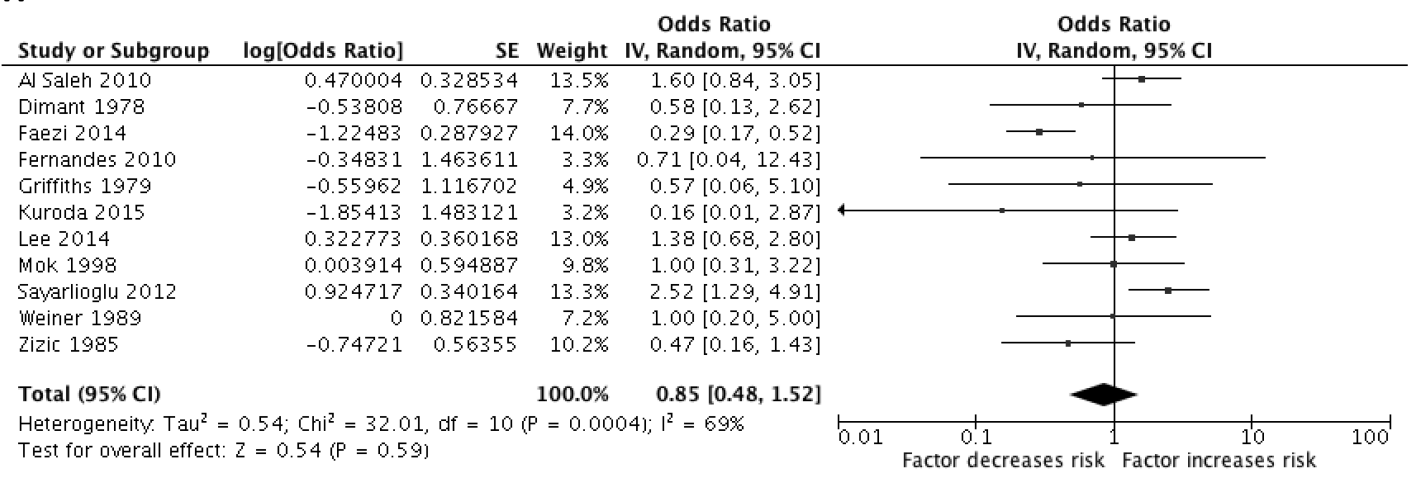

Figure 3E-H. Forest plots for clinical manifestations of SLE: E. Serositis; F. Gastrointestinal involvement; G. Hypertension; H. Oral ulcers. SLE: systemic lupus erythematosus. 


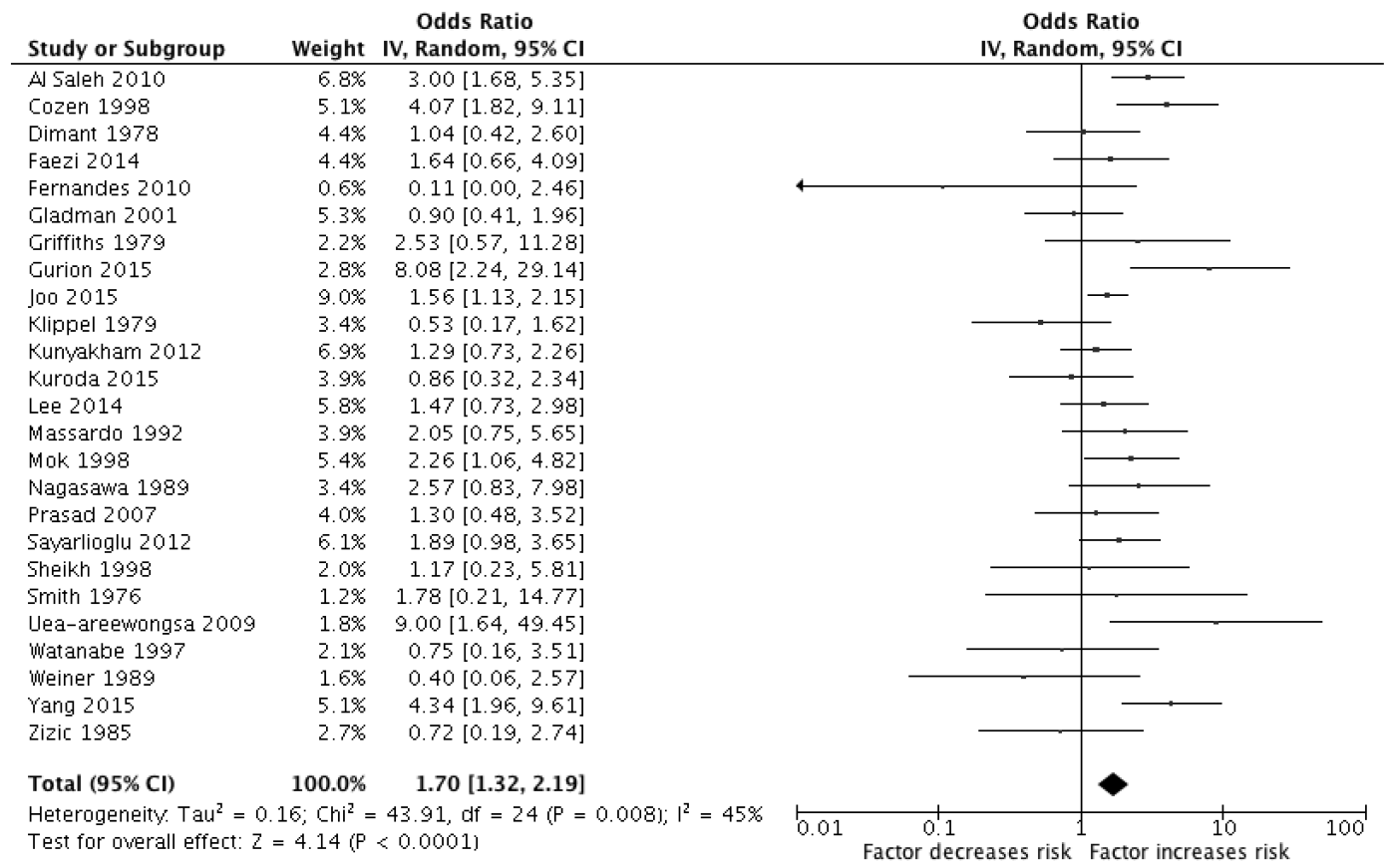

J

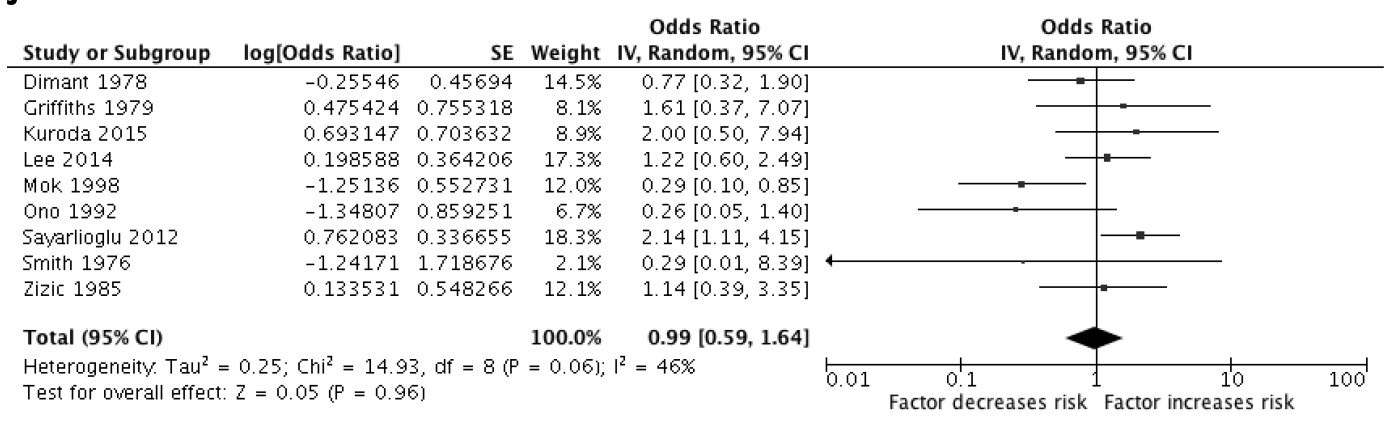

K

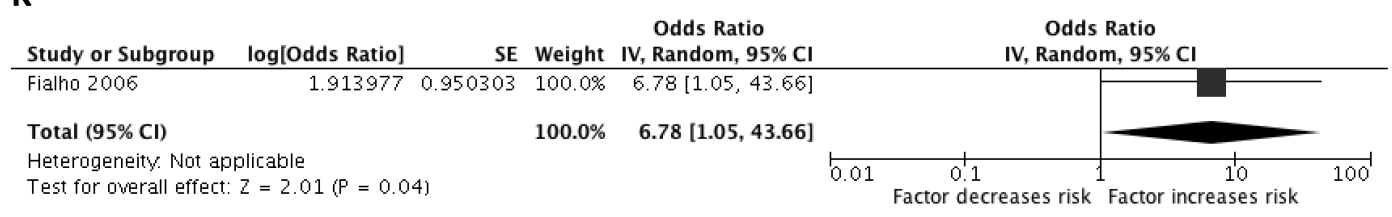

Figure 3I-K. Forest plots for clinical manifestations of SLE: I. Renal disease; J. Alopecia; K. SLEDAI > 8. SLE: systemic lupus erythematosus; SLEDAI: SLE Disease Activity Index.

systemic lupus erythematosus. Egypt Rheumatologist 2011;33:27-33.

6. Gladman D, Ginzler E, Goldsmith C, Fortin P, Liang M, Urowitz M, et al. The development and initial validation of the Systemic Lupus International Collaborating Clinics/American College of Rheumatology damage index for systemic lupus erythematosus. Arthritis Rheum 1996;39:363-9.

7. Mont MA, Hungerford DS. Non-traumatic avascular necrosis of the femoral head. J Bone Joint Surg Am 1995;77:459-74.

8. Shah KN, Racine J, Jones LC, Aaron RK. Pathophysiology and risk factors for osteonecrosis. Curr Rev Musculoskelet Med 2015; 8:201-9.

9. Fukushima W, Fujioka M, Kubo T, Tamakoshi A, Nagai M, Hirota Y. Nationwide epidemiologic survey of idiopathic osteonecrosis of the femoral head. Clin Orthop Relat Res 2010;468:2715-24.
10. Van der Goes MC, Jacobs JW, Boers M, Andrews T, Blom-Bakkers MA, Buttgereit F, et al. Monitoring adverse events of low-dose glucocorticoid therapy: EULAR recommendations for clinical trials and daily practice. Ann Rheum Dis 2010;69:1913-9.

11. Duru N, van der Goes MC, Jacobs JW, Andrews T, Boers M, Buttgereit F, et al. EULAR evidence-based and consensus-based recommendations on the management of medium to high-dose glucocorticoid therapy in rheumatic diseases. Ann Rheum Dis 2013;72:1905-13.

12. Murphey MD, Roberts CC, Bencardino JT, Appel M, Arnold E, Chang EY, et al. Expert Panel on Musculoskeletal Imaging. ACR appropriateness criteria osteonecrosis of the hip. J Am Coll Radiol 2016;13:147-55.

13. Wells G, Shea B, O'Connell D, Peterson J, Welch V, Losos M. The 


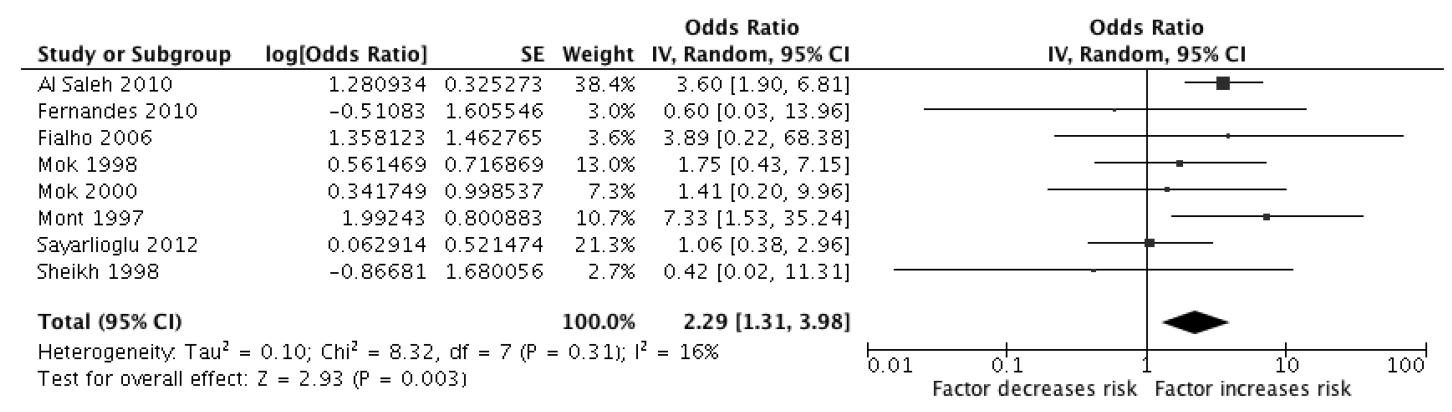

B

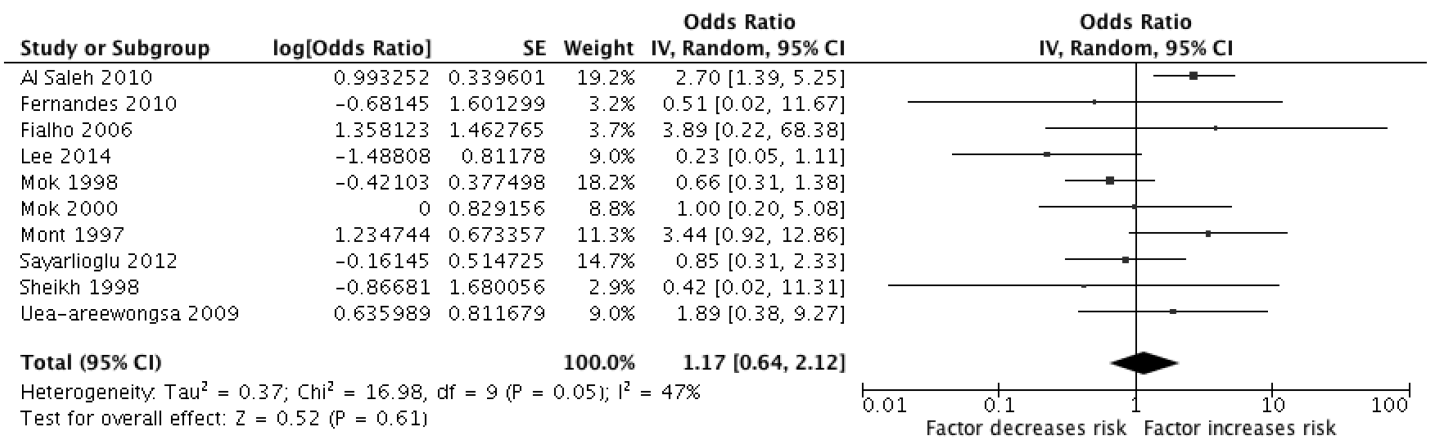

C

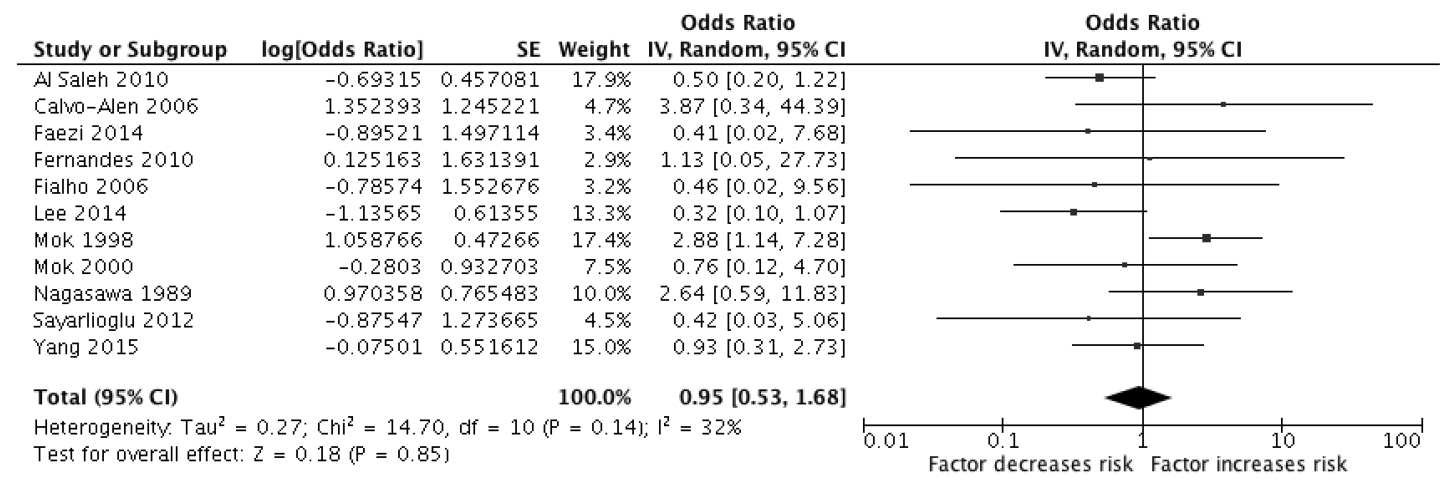

Figure 4. Forest plots for risk factors associated with laboratory results: A. Anticardiolipin antibodies IgM; B. Anticardiolipin antibodies IgG; C. Lupus anticoagulant.

Newcastle-Ottawa Scale [NOS] for assessing the quality of nonrandomised studies in meta-analyses. [Internet. Accessed May 14, 2018.] Available from: www.ohri.ca/programs/clinical_ epidemiology/oxford.asp

14. Higgins JPT, Green S. Cochrane handbook for systematic reviews of interventions version 5.1.0 [updated March 2011]. The Cochrane Collaboration. [Internet. Accessed May 14, 2018.] Available from: handbook-5-1.cochrane.org

15. DerSimonian R, Laird N. Meta-analysis in clinical trials. Control Clin Trials 1986;7:177-88.

16. Higgins JP, Thompson SG. Quantifying heterogeneity in a meta-analysis. Stat Med 2002 15;21:1539-58.

17. Gladman DD, Urowitz MB, Chaudhry-Ahluwalia V, Hallet DC, Cook RJ. Predictive factors for symptomatic osteonecrosis in patients with systemic lupus erythematosus. J Rheumatol 2001;28:761-5.

18. Gurion R, Yang H, Li H. Risk factors for the development of avascular necrosis in pediatric systemic lupus erythematosus patients [abstract]. Arthritis Rheum 2013;65:S536-S7.

19. Gurion R, Tangpricha V, Yow E, Schanberg LE, McComsey GA, Robinson AB; Atherosclerosis Prevention in Pediatric Lupus Erythematosus Investigators. Avascular necrosis in pediatric systemic lupus erythematosus: a brief report and review of the literature. Pediatr Rheumatol Online J 2015;13:13.

20. Cozen L, Wallace DJ. Avascular necrosis in systemic lupus erythematosus: clinical associations and a 47 -year perspective. Am J Orthop 1998;27:352-4.

21. Abeles M, Urman JD, Rothfield NF. Aseptic necrosis of bone in systemic lupus erythematosus. Relationship to corticosteroid therapy. Arch Intern Med 1978;138:750-4.

22. Al Saleh J, El Sayed M, Salah N, Harb D, Khan N, Mohammed N. Predictors of avascular necrosis of the hip in Emiratis patients with systemic lupus erythematosus. Egypt J Immunol 2010;17:29-40.

23. Bergstein JM, Wiens C, Fish AJ, Vernier RL, Michael A. Avascular necrosis of bone in systemic lupus erythematosus. J Pediatr 1974;85:31-5 


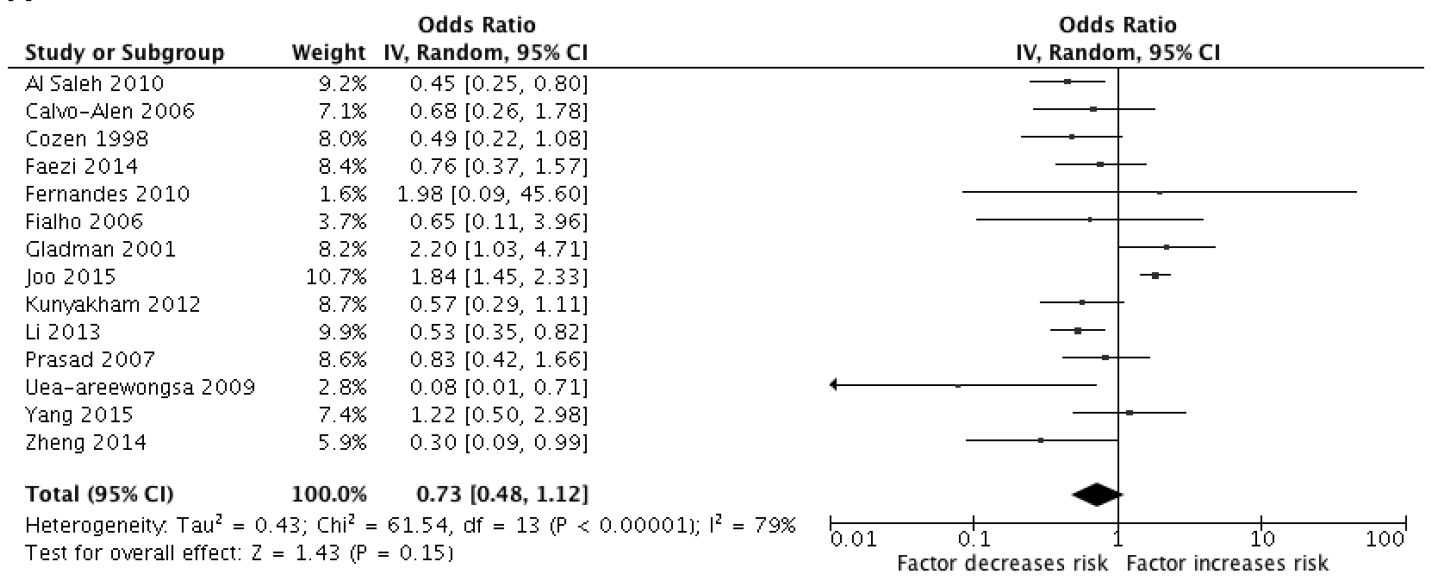

Figure 5A. Forest plots for risk factors associated with medication other than CS: A. Antimalarials. CS: corticosteroids.

24. Castro TC, Lederman H, Terreri MT, Caldana WI, Kaste SC, Hilário MO. The use of joint-specific and whole-body MRI in osteonecrosis: a study in patients with juvenile systemic lupus erythematosus. Br J Radiol 2011;84:621-8.

25. Dimant J, Ginzler EM, Diamond HS, Schlesinger M, Marino CT, Weiner $\mathrm{M}$, et al. Computer analysis of factors influencing the appearance of aseptic necrosis in patients with SLE. J Rheumatol 1978;5:136-41

26. Faezi ST, Hoseinian AS, Paragomi P, Akbarian M, Esfahanian F, Gharibdoost F, et al. Non-corticosteroid risk factors of symptomatic avascular necrosis of bone in systemic lupus erythematosus: A retrospective case-control study. Modern Rheumatology 2015;25:590-4

27. Fialho SC, Bonfá E, Vitule LF, D’Amico E, Caparbo V, Gualandro $\mathrm{S}$, et al. Disease activity as a major risk factor for osteonecrosis in early systemic lupus erythematosus. Lupus 2007;16:239-44.

28. Hagiwara S, Nakamura J, Watanabe A, Kishida S, Ohtori S, Omae $\mathrm{T}$, et al. Corticosteroids and low bone mineral density affect hip cartilage in systemic lupus erythematosus patients: Quantitative T2 mapping. J Magn Reson Imaging 2015;42:1524-31.

29. Houssiau FA, N'Zeusseu Toukap A, Depresseux G, Maldague BE, Malghem J, Devogelaer JP, et al. Magnetic resonance imaging-detected avascular osteonecrosis in systemic lupus erythematosus: lack of correlation with antiphospholipid antibodies. Br J Rheumatol 1998;37:448-53.

30. Lee J, Kwok SK, Jung SM, Min HK, Nam HC, Seo JH, et al. Osteonecrosis of the hip in Korean patients with systemic lupus erythematosus: risk factors and clinical outcome. Lupus 2014;23:39-45

31. Migliaresi S, Picillo U, Ambrosone L, Di Palma G, Mallozzi M, Tesone ER, et al. Avascular osteonecrosis in patients with SLE: relation to corticosteroid therapy and anticardiolipin antibodies. Lupus 1994;3:37-41.

32. Mok CC, Lau CS, Wong RW. Risk factors for avascular bone necrosis in systemic lupus erythematosus. Br J Rheumatol 1998;37:895-900.

33. Mok MY, Farewell VT, Isenberg DA. Risk factors for avascular necrosis of bone in patients with systemic lupus erythematosus: is there a role for antiphospholipid antibodies? Ann Rheum Dis 2000;59:462-7.

34. Nakamura J, Ohtori S, Sakamoto M, Chuma A, Abe I, Shimizu K. Development of new osteonecrosis in systemic lupus erythematosus patients in association with long-term corticosteroid therapy after disease recurrence. Clin Exp Rheumatol 2010;28:13-8.

35. Sayarlioglu M, Yuzbasioglu N, Inanc M, Kamali S, Cefle A, Karaman O, et al. Risk factors for avascular bone necrosis in patients with systemic lupus erythematosus. Rheumatol Int 2012;32:177-82.

36. Sheikh JS, Retzinger GS, Hess EV. Association of osteonecrosis in systemic lupus erythematosus with abnormalities of fibrinolysis. Lupus 1998;7:42-8.

37. Smith FE, Sweet DE, Brunner CM, Davis JS 4th. Avascular necrosis in SLE. An apparent predilection for young patients. Ann Rheum Dis 1976;35:227-32.

38. Uea-areewongsa $\mathrm{P}$, Chaiamnuay $\mathrm{S}$, Narongroeknawin $\mathrm{P}$, Asavatanabodee P. Factors associated with osteonecrosis in Thai lupus patients: a case control study. J Clin Rheumatol 2009; 15:345-9.

39. Watanabe T, Tsuchida T, Kanda N, Tamaki K. Avascular necrosis of bone in systemic lupus erythematosus. The predictive role of precipitating autoantibodies. Scand J Rheumatol 1997;26:184-7.

40. Zizic TM, Marcoux C, Hungerford DS, Dansereau JV, Stevens MB. Corticosteroid therapy associated with ischemic necrosis of bone in systemic lupus erythematosus. Am J Med 1985;79:596-604.

41. Aranow C, Zelicof S, Leslie D, Solomon S, Barland P, Norman A, et al. Clinically occult avascular necrosis of the hip in systemic lupus erythematosus. J Rheumatol 1997;24:2318-22.

42. Calvo-Alén J, McGwin G, Toloza S, Fernández M, Roseman JM, Bastian HM et al; LUMINA Study Group. Systemic lupus erythematosus in a multiethnic US cohort (LUMINA): XXIV. Cytotoxic treatment is an additional risk factor for the development of symptomatic osteonecrosis in lupus patients: results of a nested matched case-control study. Ann Rheum Dis 2006;65:785-90.

43. Kuroda T, Tanabe N, Wakamatsu A, Takai C, Sato H, Nakatsue T, et al. High triglyceride is a risk factor for silent osteonecrosis of the femoral head in systemic lupus erythematosus. Clin Rheumatol 2015;34:2071-7.

44. Ono K, Tohjima T, Komazawa T. Risk factors of avascular necrosis of the femoral head in patients with systemic lupus erythematosus under high-dose corticosteroid therapy. Clin Orthop Relat Res 1992;277:89-97.

45. Sekiya F, Yamaji K, Yang K, Tsuda H, Takasaki Y. Investigation of occurrence of osteonecrosis of the femoral head after increasing corticosteroids in patients with recurring systemic lupus erythematosus. Rheumatol Int 2010;30:1587-93.

46. Weiner ES, Abeles M. Aseptic necrosis and glucocorticosteroids in

Personal non-commercial use only. The Journal of Rheumatology Copyright $\odot$ (2018. All rights reserved 


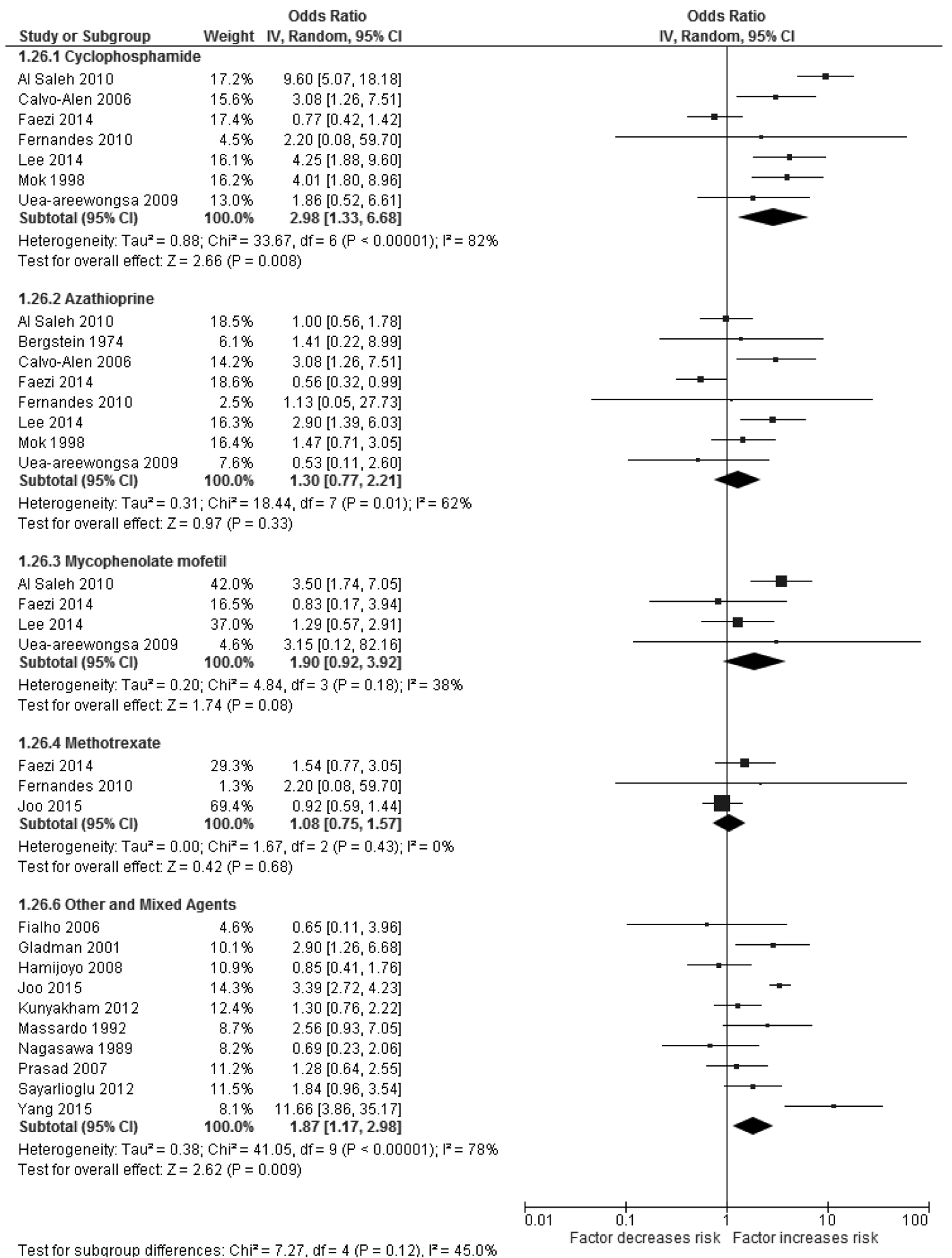

Figure $5 B$. Forest plots for risk factors associated with medication other than CS: B. Immunosuppressive agents. CS: corticosteroids.

systemic lupus erythematosus: a reevaluation. J Rheumatol 1989;16:604-8.

47. Klippel JH, Gerber LH, Pollak L, Decker JL. Avascular necrosis in systemic lupus erythematosus. Silent symmetric osteonecrosis. Am J Med 1979;67:83-7.

48. Nagasawa K, Ishii Y, Mayumi T, Tada Y, Ueda A, Yamauchi Y, et al.
Avascular necrosis of bone in systemic lupus erythematosus: possible role of haemostatic abnormalities. Ann Rheum Dis 1989;48:672-6.

49. Nakamura J, Saisu T, Yamashita K, Suzuki C, Kamegaya M, Takahashi K. Age at time of corticosteroid administration is a risk factor for osteonecrosis in pediatric patients with systemic lupus

Personal non-commercial use only. The Journal of Rheumatology Copyright @ 2018 . All rights reserved. 
erythematosus: a prospective magnetic resonance imaging study. Arthritis Rheum 2010;62:609-15.

50. Shigemura T, Nakamura J, Kishida S, Harada Y, Ohtori S, Kamikawa K, et al. Incidence of osteonecrosis associated with corticosteroid therapy among different underlying diseases: prospective MRI study. Rheumatol 2011;50:2023-8.

51. Shigemura T, Nakamura J, Harada Y. Incidence of steroid-associated osteonecrosis of the talus: a prospective MRI study. Eur Orthop Traumatol 2013;4:237-40.

52. Hamijoyo L, Llamado LJ, Navarra SV. Risk factors for avascular necrosis among Filipino patients with systemic lupus erythematosus. Int J Rheum Dis 2008;2:141-7.

53. Joo YB, Sung YK, Shim JS, Kim JH, Lee EK, Lee HS, et al. Prevalence, incidence, and associated factors of avascular necrosis in Korean patients with systemic lupus erythematosus: a nationwide epidemiologic study. Rheumatol Int 2015;35:879-86.

54. Massardo L, Jacobelli S, Leissner M, González M, Villarroel L, Rivero S. High-dose intravenous methylprednisolone therapy associated with osteonecrosis in patients with systemic lupus erythematosus. Lupus 1992;1:401-5.

55. Nagasawa K, Tada Y, Koarada S, Horiuchi T, Tsukamoto H, Murai $\mathrm{K}$, et al. Very early development of steroid-associated osteonecrosis of femoral head in systemic lupus erythematosus: prospective study by MRI. Lupus 2005;14:385-90.

56. Yang XY, Xu DH. MDR1(ABCB1) gene polymorphisms associated with steroid induced osteonecrosis of femoral head in systemic lupus erythematosus. Pharmazie 2007;62:930-2.

57. Yang Y, Kumar S, Lim LS, Silverman ED, Levy DM. Risk factors for symptomatic avascular necrosis in childhood-onset systemic lupus erythematosus. J Rheumatol 2015;42:2304-9.

58. Petri M. Musculoskeletal complications of systemic lupus erythematosus in the Hopkins Lupus Cohort: an update. Arthritis Care Res 1995;8:137-45.

59. Fernandes EG, Guissa VR, Saviolli C, Siqueira JT, Valente M, da Silva CA. Osteonecrosis of the jaw on imaging exams of patients with juvenile systemic lupus erythematosus. Rev Bras Reumatol 2010;50:3-15.
60. Griffiths ID, Maini RN, Scott JT. Clinical and radiological features of osteonecrosis in systemic lupus erythematosus. Ann Rheum Dis 1979;38:413-22.

61. Kunyakham W, Foocharoen C, Mahakkanukrauh A, Suwannaroj S, Nanagara R. Prevalence and risk factor for symptomatic avascular necrosis development in Thai systemic lupus erythematosus patients. Asian Pac J Allergy Immunol 2012;30:152-7.

62. Li X, Ren Q, Chen Z, Li X, Wang G. Risk factors for avascular necrosis in patients with systemic lupus erythematosus [abstract]. Int J Rheum Dis Suppl 2013;16 Suppl 1:1-48.

63. Tektonidou MG, Malagari K, Vlachoyiannopoulos PG, Kelekis DA, Moutsopoulos HM. Asymptomatic avascular necrosis in patients with primary antiphospholipid syndrome in the absence of corticosteroid use: a prospective study by magnetic resonance imaging. Arthritis Rheum 2003;48:732-6.

64. Zheng W, Wu HH, Wu X, Zhao Y, Zeng XF, Zhang FC. Clinical features of SLE patients with knee osteonecrosis [abstract]. Int J Rheum Dis 2014;68:0238.

65. Zonana-Nacach A, Barr SG, Magder LS, Petri M. Damage in systemic lupus erythematosus and its association with corticosteroids. Arthritis Rheum 2000;43:1801-8.

66. Espinola RG, Pierangeli SS, Gharavi AE, Harris EN. Hydroxychloroquine reverses platelet activation induced by human IgG antiphospholipid antibodies. Thromb Haemost 2002;87:518-22.

67. Wallace DJ, Metzger AL, Stecher VJ, Turnbull BA, Kern PA. Cholesterol-lowering effect of hydroxychloroquine in patients with rheumatic disease: reversal of deleterious effects of steroids on lipids. Am J Med 1990;89:322-6.

68. Seleznick MJ, Silveira LH, Espinoza LR. Avascular necrosis associated with anticardiolipin antibodies. J Rheumatol 1991;18:1416-7.

69. Nevskaya T, Gamble MP, Pope JE. A meta-analysis of avascular necrosis in systemic lupus erythematosus: prevalence and risk factors. Clin Exp Rheumatol 2017;35:700-10.

70. Zhu KK, Xu WD, Pan HF, Zhang M, Ni J, Ge FY, et al. The risk factors of avascular necrosis in patients with systemic lupus erythematosus: a meta-analysis. Inflammation 2014;37:1852-64. 